ARTICLE

Received 12 Sep 2014 | Accepted 27 Mar 2015 | Published 19 May 2015

DOI: $10.1038 /$ ncomms 8090

OPEN

\title{
Intestinal intraepithelial lymphocyte activation promotes innate antiviral resistance
}

Mahima Swamy $1,2,3$, Lucie Abeler-Dörner ${ }^{1,2, \star}$, James Chettle ${ }^{4, \star}$, Tanel Mahlakõiv ${ }^{5,6, \star}$, Delphine Goubau1, Probir Chakravarty ${ }^{1}$, George Ramsay ${ }^{3}$, Caetano Reis e Sousa ${ }^{1}$, Peter Staeheli ${ }^{5}$, Barbara A. Blacklaws ${ }^{4}$, Jonathan L. Heeney ${ }^{4} \&$ Adrian C. Hayday ${ }^{1,2}$

Unrelenting environmental challenges to the gut epithelium place particular demands on the local immune system. In this context, intestinal intraepithelial lymphocytes (IEL) compose a large, highly conserved T cell compartment, hypothesized to provide a first line of defence via cytolysis of dysregulated intestinal epithelial cells (IEC) and cytokine-mediated re-growth of healthy IEC. Here we show that one of the most conspicuous impacts of activated IEL on IEC is the functional upregulation of antiviral interferon (IFN)-responsive genes, mediated by the collective actions of IFNs with other cytokines. Indeed, IEL activation in vivo rapidly provoked type I/III IFN receptor-dependent upregulation of IFN-responsive genes in the villus epithelium. Consistent with this, activated IEL mediators protected cells against virus infection in vitro, and pre-activation of IEL in vivo profoundly limited norovirus infection. Hence, intraepithelial T cell activation offers an overt means to promote the innate antiviral potential of the intestinal epithelium.

\footnotetext{
${ }^{1}$ Immunosurveillance lab, Francis Crick Institute, Lincoln's Inn Fields Laboratories, London WC2A 3LY, UK. ${ }^{2}$ Peter Gorer Department of Immunobiology, King's College London, Borough Wing, Guy's Hospital, Great Maze Pond, London SE1 9RT, UK. ${ }^{3}$ Cell Signalling and Immunology, College of Life Sciences, University of Dundee, Dow Street, Dundee DD1 5EH, UK. ${ }^{4}$ Department of Veterinary Medicine, University of Cambridge, Cambridge CB3 OES, UK. ${ }^{5}$ Institute of Virology, University Medical Center, Freiburg D-79104, Germany. ${ }^{6}$ Spemann Graduate School of Biology and Medicine, Albert Ludwigs University Freiburg, Freiburg, Germany. ${ }^{\star}$ These authors contributed equally to this work.. Correspondence and requests for materials should be addressed to M.S. (email: m.swamy@dundee.ac.uk) or A.H. (email: adrian.hayday@kcl.ac.uk).
} 
ntraepithelial lymphocytes (IEL) compose a very large $\mathrm{T}$ cell compartment conserved in all vertebrates. Thus, intestinal IEL exist from fish through mice to humans. Despite their conservation, and their decades'-old description, IEL remain very poorly understood, particularly in humans ${ }^{1}$. This situation cannot sustain, given the cells' juxtaposition to the intestinal microbiota that are increasingly acknowledged to regulate many aspects of health and disease. Thus, there is a growing pressure to use animal models to clarify the diversity and basic biology of IEL.

Murine small intestinal IEL comprise roughly equal numbers of $\gamma \delta$ and $\alpha \beta$ T cells. One type of IEL (previously termed Type $a$ ) expresses $\mathrm{T}$ cell antigen receptor (TCR) $\alpha \beta$ and $\mathrm{CD} 8 \alpha \beta$ and comprises mostly Tissue-resident memory $\left(\mathrm{T}_{\mathrm{RM}}\right)$ cells recruited to the epithelium after systemic priming ${ }^{1,2}$. The second type of IEL (Type $b$ ) expresses either TCR $\alpha \beta$ or TCR $\gamma \delta$, and is either CD $8 \alpha \alpha^{+}$ or $\mathrm{CD} 8{ }^{-} \mathrm{CD} 4^{-}$(so-called double negative cells). Type $b$ IEL are the more common type in unchallenged mice and seemingly enter the small intestinal epithelium directly upon maturation, rather than experiencing a systemic phase ${ }^{3}$. Furthermore, many are considered to be agonist selected and reactive to auto-antigens, although there is scant direct evidence for this ${ }^{4}$.

Both IEL sub-compartments contain cells that can be rapidly activated via TCR-dependent and/or TCR-independent stimulation, permitting them to influence the afferent phase of an immune response rather than solely the delayed efferent phasethe traditional arena of $\mathrm{T}$ cell responses ${ }^{1,5}$. Many studies have focused on the potent cytotoxicity of activated IEL $^{6}$, their promotion of epithelial repair $^{7}$, and their capacity to recruit other immune-protective and immune-regulatory cells. Indeed, within hours of activation, skin and/or gut IEL can produce very large amounts of biologically active soluble mediators, including granzymes, cytokines and chemotactic factors ${ }^{6-8}$. Conversely, the potential of IEL to contribute key, anti-pathogen responses has not been so clear.

Given the plethora of bacteria in the gut and its potential to regulate $\mathrm{T}$ cell composition and function ${ }^{9-11}$, there has predictably been interest in the role of IEL in anti-microbial responses. Thus, recently reported work, consistent with the contribution of TCR $\gamma \delta^{+}$IEL to the immediate phase of immune responses, demonstrated the cells' capacity to limit bacterial dissemination during the first few hours following infection with Salmonella enterica ser. Typhimurium. This activity was mainly dependent on cell-intrinsic production of the antibacterial defensin, RegIII $\gamma^{12}$. Likewise, earlier work demonstrated both immunoregulatory and immunoprotective roles for murine IEL in the response to the natural and ubiquitous gut-tropic infectious protozoan parasite, Eimeria ${ }^{13-15}$.

Enteroviruses, including coxsackieviruses, rotavirus and norovirus, cause debilitating disease in neonates, but often much milder disease in adults, a phenomenon frequently attributed to the relative immaturity of the neonatal gut immune compartment $^{16}$. Of note, IEL numbers are low at birth and during weaning, but expand substantially thereafter, coinciding with the reduced susceptibility of adult mice to multiple viruses ${ }^{4,17,18}$. Added to this, IEL expand after systemic infection with lymphocytic choriomeningitis virus ${ }^{19}$ and during oral infection by reovirus and rotavirus ${ }^{20,21}$. Within $48 \mathrm{~h}$ of infection, interferon$\gamma$ (IFN $\gamma)$ production was increased, as was the cells' cytotoxic activity. Moreover, the cytotoxic activity of primed IEL specifically targeted virus-infected cells in culture ${ }^{22}$. Collectively, these findings strongly argued for the further investigation of how IEL activation might promote virus-resistance within the epithelium.

To accomplish this, we have employed two strategies. First, a recently developed protocol for culturing IEL-permitted IEL-intestinal epithelial cell (IEC) interactions to be studied in vitro. Second, these interactions were validated in vivo by examining the molecular and biological impact upon IEC of IEL activated by the intraperitoneal (i.p.) administration of anti-CD3. Unexpectedly, one of the most conspicuous impacts of activated IEL upon IEC was the upregulation of IFN-stimulated genes (ISGs) and of the antiviral response, attributable to the production of type I, II and III IFNs by IEL. Consistent with this, activated IEL supernatants rendered epithelial cells more resistant to virus infection in vitro. Moreover, $\mathrm{T}$ cell activation in vivo rapidly induced ISGs in the villus epithelium in mice, corresponding with greatly enhanced resistance to murine norovirus (MNV) within $40 \mathrm{~h}$ of gastrointestinal infection. By identifying a novel and powerful potential for intestinal $\mathrm{T}$ lymphocytes to regulate the innate antiviral defences of the surrounding stroma, these findings underline the innate-like biology of the IEL compartment and its importance for body surface integrity.

\section{Results}

IEL activate antiviral responses in epithelial cells. To examine how soluble effectors produced by activated IEL might impact upon IEC, we prepared microarray gene expression profiles of the widely used, murine small intestinal epithelial cell line MODE-K after treating it for $18 \mathrm{~h}$ with supernatants of IEL that had been exposed for $24 \mathrm{~h}$ either to agonistic TCR cross-linking or to control antibodies. Because IEL rapidly die ex vivo, particularly when challenged with TCR agonists, activated IEL supernatants are invariably contaminated with products of stressed and dying cells. To avoid this, a recently developed culture system (ref. 23 and see Methods) was employed that maintains IEL in a highly viable state for over 2 weeks, permitting them to be grown out and rested before re-activation. Relative to the starting preparation, the cultures at 13 days post-establishment comprised essentially pure T cells (Supplementary Fig. 1a,b), removing, for the first time, the possibility that mediators attributed to IEL might be the products of contaminating cell types. The cultures largely preserved the subset composition of the $\gamma \delta$ T cell compartment (Supplementary Fig. 1a,b), thereby permitting assay of type $b$ IEL. The subset complexity of TCR $\alpha \beta^{+}$IEL, comprising both type $a$ and type $b$ cells was also preserved, albeit that the cells' relative representation changed over time (Supplementary Fig. 1a,b).

The IEL were re-activated by exposure to plate-bound anti-CD3 (ref. 23) following which supernatants were collected. RNA expression profiles from MODE-K cells treated with activated and resting IEL supernatants from several biologically independent cultures were analysed and compared on an Illumina platform. By comparison to medium alone or to supernatant from unstimulated IEL, the supernatant of anti-CD3-activated IEL profoundly impacted upon MODE-K cells, with many genes overtly upregulated, and others strongly downregulated (Fig. 1a). This study focuses on the unexpected finding that 22 of the 50 most upregulated genes related to antiviral functions (Table 1). Indeed, Metacore Genego pathway enrichment analysis showed that the top four pathways upregulated comprised IFN-regulated genes associated with antiviral activity (Fig. 1b), including $M \times 2$, Rsad2 (Viperin), multiple Oas genes, Ifit3 and Bst2 (Tetherin; Table 1).

The upregulation of ISGs in MODE-K cells cultured either with IEL supernatant or with IEL in the presence of anti-CD3 was confirmed by quantitative reverse transcription-PCR (qRT-PCR), extending the ISGs analysed to other well-characterized examples, for example, Ifit1, Mx1, Adar, Oas1g and $\mathrm{Pkr}$ (eif2ak2) (Fig. 1c). Although some other ISGs, for example, Ifih1 (MDA5) and Ifitm1/2 were not upregulated, it is known that different cell types stimulated with IFNs under different circumstances induce discrete sub-groups within the full spectrum of ISGs ${ }^{24-26}$.

IEL supernatants were initially applied to MODE-K cells for $18 \mathrm{~h}$. However, subsequent experiments showed that some ISGs 
a

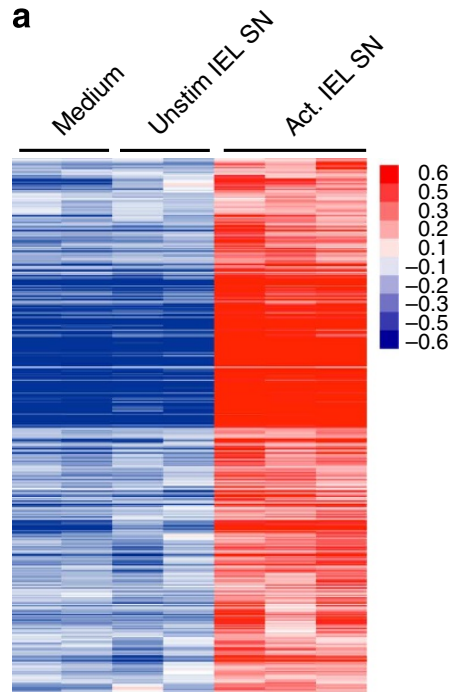

b

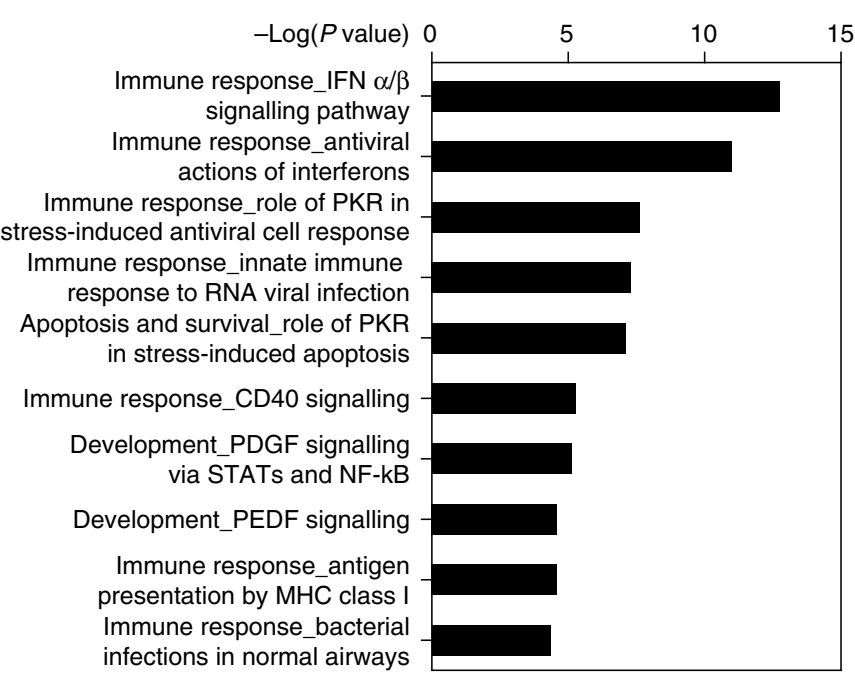

c
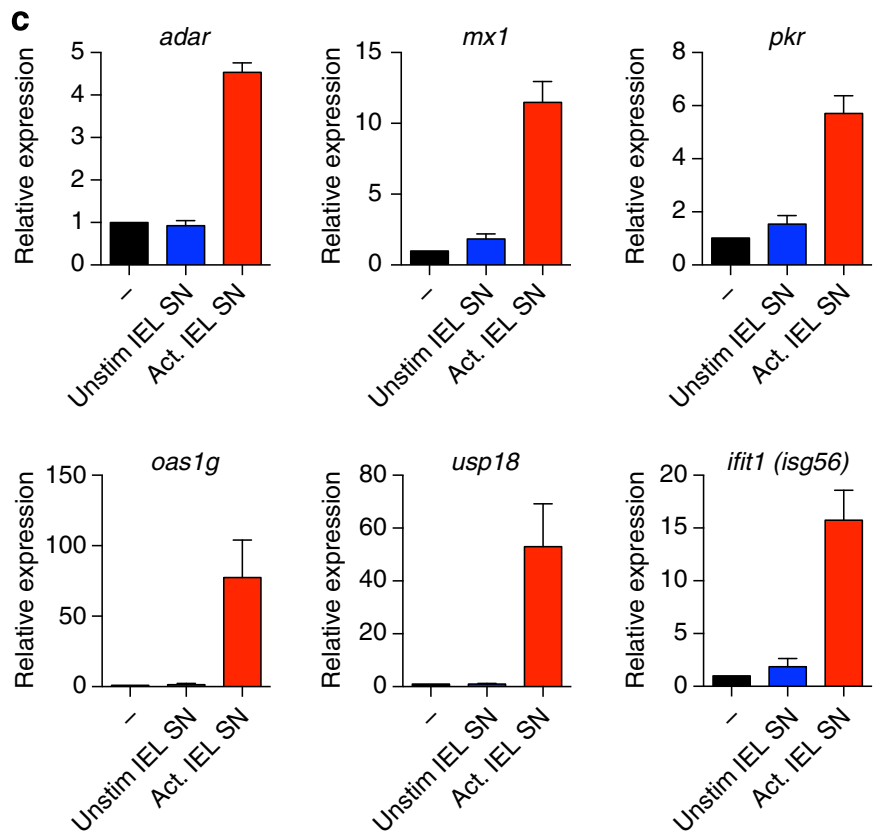

Figure 1 | IEL supernatant (SN) induces antiviral defence pathways in IEC. (a) Hierarchical clustering of differentially expressed genes in MODE-K cells treated with SN from unstimulated cultured IEL and SN from IEL activated on plate-bound anti-CD3 for $24 \mathrm{~h}$, in comparison to genes expressed in MODE-K cultured in medium alone. Heatmap key: red = higher expression, blue=lower expression relative to the mean expression of the gene across all samples. (b) Genes upregulated in MODE-K by stimulated IEL SN relative to unstimulated IEL SN were subjected to enrichment analysis using Metacore. Shown are the top ten statistically significant pathways, calculated using an adjusted $P$ value of 0.05 . (c) Confirmation by qRT-PCR of upregulation of some antiviral genes. MODE-K cells were cultured for $18 \mathrm{~h}$ with medium, anti-CD3, or SN from cultured IEL as in a. Data are the mean and s.e.m. of three to five independent experiments calculated as fold change relative to the untreated samples. See also Supplementary Fig. 1.

were upregulated within $6 \mathrm{~h}$, strongly suggesting them to be direct responses to activated IEL effectors (Supplementary Fig. 1c). Moreover, increases in expression could be achieved with supernatants from IEL that had been activated for just $2-3 \mathrm{~h}$, implying that the IEL mediators responsible for the induced antiviral signatures in epithelial cells were produced immediately upon anti-CD3 stimulation (Supplementary Fig. 1d). Last and notably, both $\mathrm{TCR} \alpha \beta^{+}$and TCR $\gamma \delta^{+}$IEL could evoke this response in MODE-K cells, as stimulation of essentially pure, IEL-derived T cell cultures (Supplementary Fig. 1b) with either anti-TCR $\beta$ or anti-TCR $\gamma \delta$ antibodies induced the IEC response signature (Supplementary Fig. 1e).
Activated IEL upregulate type I and III IFNs. ISGs are induced by IFNs, primarily type I IFN (including IFN- $\alpha / \beta$ ) and type III IFN (IFN- $\lambda 2, \lambda 3$, also known as interleukin (IL)-28a,b in the mouse $)^{24-26}$. To test whether activated TCR $\gamma \delta^{+}$ and/or TCR $\alpha \beta^{+}$IEL produce IFNs, IEL were this time flow-sorted ex vivo to substantially pre-enrich for either TCR $\alpha \beta^{+}$or TCR $\gamma \delta^{+}$CD $8 \alpha \alpha$ IEL (Supplementary Fig. 2a), and then cultured for 12-14 days before being stimulated for $2 \mathrm{~h}$ by anti-CD3 stimulation. Although the composition of the sorted cells changed somewhat in culture, the respective subsets remained greatly enriched for TCR $\alpha \beta^{+}$IEL and $\gamma \delta$ IEL (Supplementary Fig. 2b), and in each case, substantial 
Table 1 | Top 50 genes upregulated by activated IEL supernatant activity in MODE-K cells, relative to treatment with unstimulated IEL supernatant ${ }^{\star}$.

\begin{tabular}{|c|c|c|c|}
\hline & Gene symbol & Fold upregulation & $P$ value \\
\hline 1 & Gbp1 & 65.55766376 & $3.95 \mathrm{E}-021$ \\
\hline 2 & Cxcl10 & 58.95340945 & $1.53 \mathrm{E}-014$ \\
\hline 3 & Gbp2 & 45.85247206 & $6.76 \mathrm{E}-020$ \\
\hline 4 & lgtp & 40.83377732 & $1.15 \mathrm{E}-020$ \\
\hline 5 & Ifit3 & 31.77914902 & $3.42 \mathrm{E}-020$ \\
\hline 6 & Parp14 & 31.21626222 & $1.53 \mathrm{E}-019$ \\
\hline 7 & $\mathrm{Cxc} / 9$ & 29.62707481 & $1.29 E-013$ \\
\hline 8 & Gbp3 & 28.79272785 & $2.12 \mathrm{E}-021$ \\
\hline 9 & $\operatorname{Irgm} 2$ & 23.32336086 & $1.76 \mathrm{E}-019$ \\
\hline 10 & Usp18 & 20.3973229 & 1.71E-015 \\
\hline 11 & Serpina3f & 19.21505748 & $5.53 \mathrm{E}-019$ \\
\hline 12 & $C d 274$ & 18.76071204 & $3.20 \mathrm{E}-017$ \\
\hline 13 & Oas1g & 16.84099589 & $2.24 \mathrm{E}-017$ \\
\hline 14 & Uba7 & 16.65088632 & $1.20 \mathrm{E}-017$ \\
\hline 15 & $\operatorname{lsg} 15$ & 15.20627377 & $2.76 \mathrm{E}-020$ \\
\hline 16 & Ubd & 14.98105332 & $1.05 \mathrm{E}-015$ \\
\hline 17 & Tap2 & 14.66831575 & $4.86 \mathrm{E}-014$ \\
\hline 18 & Ifi47 & 13.4774931 & 2.36E-017 \\
\hline 19 & Oas/2 & 12.64280486 & 6.04E-015 \\
\hline 20 & Cxcl1 & 12.61727906 & $1.55 \mathrm{E}-015$ \\
\hline 21 & Serpina3g & 12.40164805 & $3.76 \mathrm{E}-015$ \\
\hline 22 & Bst2/Tetherin & 12.22500541 & 4.71E-012 \\
\hline 23 & Irgm1 & 12.0682483 & 8.27E-020 \\
\hline 24 & Batf2 & 12.00016517 & $3.09 E-016$ \\
\hline 25 & Casp4 & 11.92209136 & $5.60 \mathrm{E}-015$ \\
\hline 26 & $M \times 2$ & 11.8635847 & $5.14 \mathrm{E}-014$ \\
\hline 27 & Gbp6 & 11.36566559 & $1.15 \mathrm{E}-015$ \\
\hline 28 & Ly6a & 11.00935367 & $2.41 \mathrm{E}-017$ \\
\hline 29 & Psmb10 & 10.89082162 & $4.22 \mathrm{E}-014$ \\
\hline 30 & Irf1 & 10.86880156 & $7.63 \mathrm{E}-016$ \\
\hline 31 & Rsad2/Viperin & 10.59057187 & $1.56 \mathrm{E}-014$ \\
\hline 32 & Clec2d & 9.59559145 & $3.03 E-018$ \\
\hline 33 & Gvin1 & 9.352420697 & $3.19 E-016$ \\
\hline 34 & H2-T23 & 9.232998263 & $2.56 \mathrm{E}-020$ \\
\hline 35 & $\mathrm{Ccl} 5$ & 8.209346619 & $1.70 \mathrm{E}-007$ \\
\hline 36 & Oas2 & 8.03980934 & $8.21 \mathrm{E}-015$ \\
\hline 37 & $1 / 15$ & 7.420256815 & 1.19E-015 \\
\hline 38 & Samd9I & 7.264056178 & $5.63 \mathrm{E}-016$ \\
\hline 39 & Tap1 & 7.198593767 & $4.95 \mathrm{E}-017$ \\
\hline 40 & Lgals3bp & 7.069264112 & $2.35 \mathrm{E}-013$ \\
\hline 41 & Stat1 & 6.934514582 & $3.55 E-014$ \\
\hline 42 & Hap1 & 6.666286165 & $1.55 \mathrm{E}-014$ \\
\hline 43 & Ly6c1 & 6.544184369 & $1.98 \mathrm{E}-016$ \\
\hline 44 & Tgtp & 6.533063036 & $2.05 \mathrm{E}-017$ \\
\hline 45 & Ube216 & 6.319678326 & $6.88 \mathrm{E}-017$ \\
\hline 46 & Tapbp & 5.946552674 & 9.86E-011 \\
\hline 47 & $\| 17 r / 1$ & 5.882100485 & 3.19E-011 \\
\hline 48 & Fas & 5.870197407 & $1.72 \mathrm{E}-015$ \\
\hline 49 & $\mathrm{Ccl} 2$ & 5.760057637 & $3.58 \mathrm{E}-007$ \\
\hline 50 & Trim21 & 5.550994810 & $4.38 \mathrm{E}-017$ \\
\hline
\end{tabular}

IEL, intraepithelial lymphocyte.

${ }^{*}$ Only one probe per gene and only known genes are shown, and those involved in antiviral pathways or with putative antiviral function are highlighted.

increases in Ifna mRNA were provoked by TCR agonist stimulation (Fig. 2a). Ifnl mRNA was also rapidly upregulated albeit to a lesser extent than known products of IEL activation such as tumour necrosis factor (TNF) and IFN $\gamma$ (Fig. 2a).

These results were consistent with the finding (above) that either anti-TCR $\beta$ or anti-TCR $\gamma \delta$ antibody treatment of IEL cultures induced the IEC response signature. We therefore checked that similar responses would be induced in IEL that were flow-sorted directly ex vivo, briefly rested, and then activated before any culturing. Indeed, they too upregulated transcription of Ifna, Ifnl and Ifng mRNAs (Supplementary Fig. 2c).

Of note, supernatants of cultured IEL that had been activated for $18 \mathrm{~h}$ accumulated IFN $\alpha$ sufficient to be easily measurable by ELISA (Fig. 2b), and to trigger luciferase expression in cells transfected with an ISRE-containing promoter responsive to type I and type III IFNs (Fig. 2c). Thus, TCR-mediated activation of IEL can rapidly trigger functionally competent type I and type III IFNs, in addition to its induction of conventional T effector cytokines.

TCR-triggered production of type I IFNs has been previously documented in $\mathrm{CD} 8{ }^{+} \mathrm{T}$ cells ${ }^{27}$, but the pathway leading to this induction was not elucidated. The transcription of type I and type III IFNs is generally induced by Interferon Regulatory Factors, IRF3 and IRF7 (refs 28,29), contingent on their phosphorylation by TBK1/IKKe that promotes their nuclear translocation and transcriptional targeting ${ }^{30}$. Consistent with their expression of type I and type III IFNs, IEL constitutively express Irf7 mRNA, which encodes a limiting transcriptional regulator of IFN production (Supplementary Fig. 2c; Serial analysis of gene expression data, gene expression omnibus (GEO) accession code GSE63090 (ref. 6)), while TCR triggering of resting IEL induced phosphorylation of TBK1/IKKE on the activation loop Ser172 (Fig. 2d and Supplementary Fig. 2d). Furthermore, the induction after $2 \mathrm{~h}$ of Ifna and Ifnl mRNAs was clearly reduced by inhibition of IKKe/TBK1 by MRT67307 (ref. 31 ), whereas this had little effect on Ifng upregulation, which was instead reduced by NG-25 that inhibits TAK1 (albeit with some impact on Lck; Fig. 2e). The fact that NG-25 also inhibited Ifna and Ifnl mRNA induction is consistent with TCR-dependent TAK1-mediated phosphorylation of TBK1/IKK. Collectively, these data offer a basic molecular mechanism by which type I and III IFNs may be induced in IEL directly by TCR triggering.

The co-expression by activated IEL of type I, II and III IFNs and TNF is provocative given that these may cooperatively and variably regulate different gene sets. For example, blocking the type I IFN receptor (IFNAR-1) on MODE-K cells during culture with IEL supernatant substantially impaired induction of $M x 1$, Usp18 and other ISGs (Supplementary Fig. 3a), whereas the blocking antibody did not affect Irfl, which is known to be induced very strongly by IFN $\gamma$ and not by IFN $\alpha$ (ref. 24; Supplementary Fig. 3a). Indeed, upregulation of each gene tested was reduced to baseline levels by simultaneously blocking the response to more than one IFN/cytokine. We did not use blocking antibodies against IFNlambda receptor (IFNLR, IL28R), as MODE-K cells do not express mRNA for this receptor (Supplementary Fig. 3b). However, because IFN $\lambda$ produced by IEL may also contribute in vivo to ISG upregulation in primary epithelial cells expressing IFNLR, the studies described below continued to focus on both type I IFN and IFN $\lambda$ (type III IFN).

Activated IEL protect epithelial cells from virus infection. If activated IEL supernatant is a source of type I IFN and IFN $\lambda$, we would predict that it should protect cells from virus infection. To test this, supernatant of cultured IEL, with or without TCRmediated stimulation (Act or Unstim) was added to MODE-K cell cultures that were then infected with encephalomyocarditis virus (EMCV), which induces a cytopathic effect in many murine cell types. As indicated by crystal violet staining of living cells (Fig. 3a,b), EMCV efficiently killed MODE-K cells even at low multiplicity of infection (MOI). This cytopathic effect was reduced by adding anti-CD3-activated IEL supernatant to MODE-K cells before infection, whereas supernatants from resting IEL had no appreciable effect (Fig. 3c). The protective effect was roughly comparable to that of $500 \mathrm{U} \mathrm{ml}^{-1}$ of recombinant IFN $\alpha$, showing the potency of IEL activation in protecting 
a
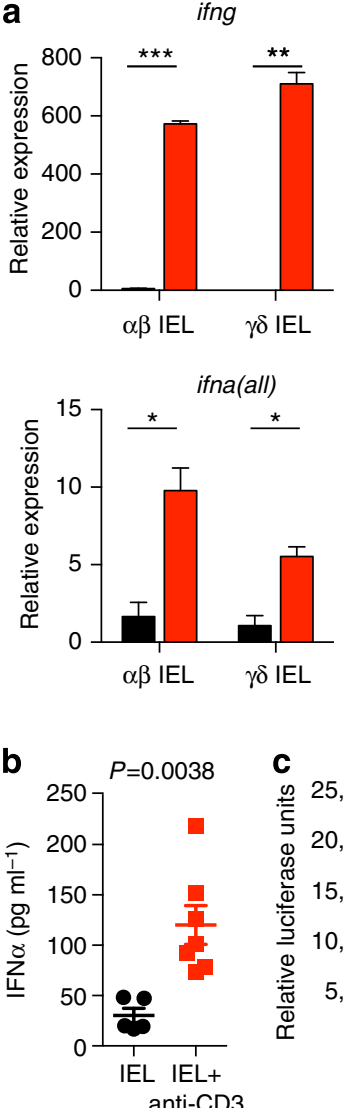
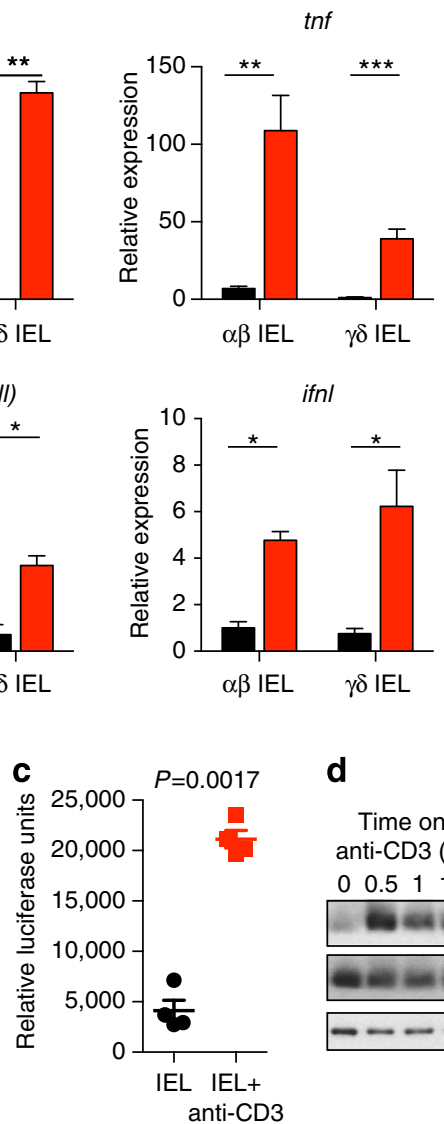

d
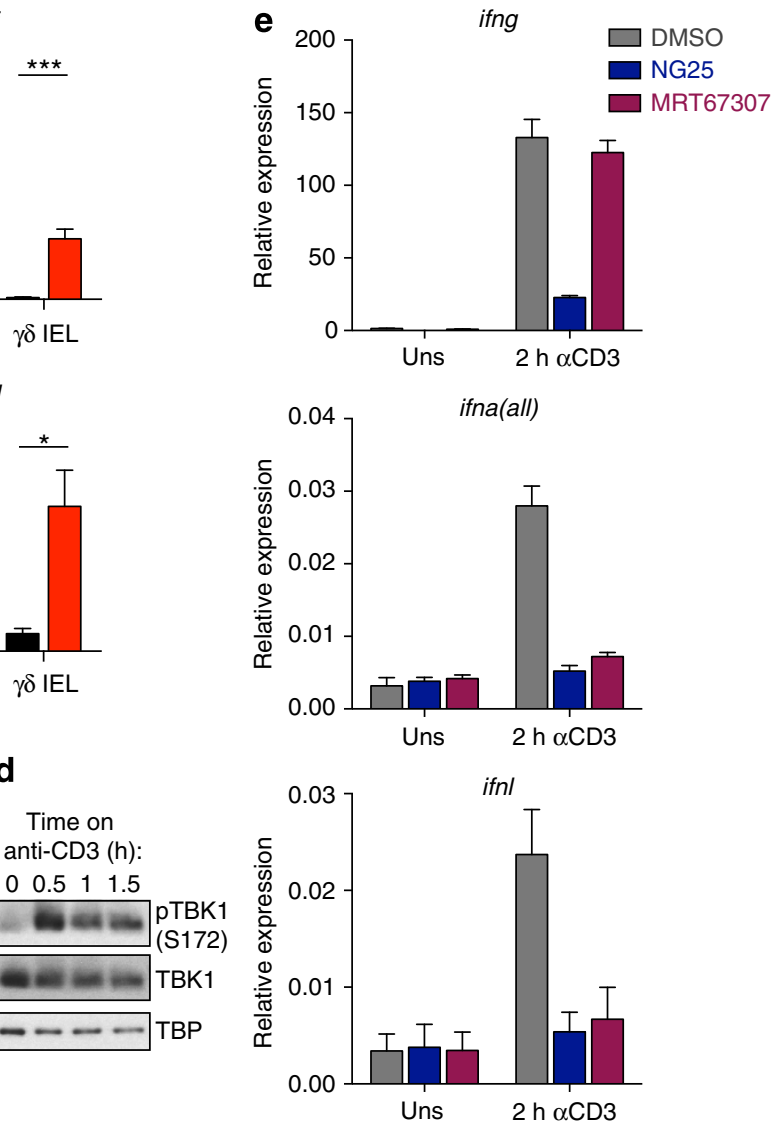

Figure 2 | IEL produce type I and III IFN upon stimulation through activation of TBK1. (a) qRT-PCR showing expression of type I, II, III IFN mRNA and TNF mRNA in IEL sorted into TCR $\gamma \delta^{+} \mathrm{CD} 8 \alpha \alpha^{+}$and TCR $\alpha \beta^{+} \mathrm{CD} 8 \alpha \alpha^{+}$subsets, cultured and then stimulated with anti-CD3 for $2 \mathrm{~h}$ (red bars). Data are the mean and s.e.m. of IEL from three mice. (b) IFN $\alpha$ was measured in resting and activated (18h) IEL (cultured) supernatant by ELISA. Each point represents an independent culture, $n=7$. (c) IEL supernatant was assayed for the presence of active IFN by ISRE-luciferase reporter assay, $n=4$. Statistical significance was calculated in a-c by two-tailed unpaired $t$-tests, ${ }^{\star} P<0.05,{ }^{\star \star} P<0.01,{ }^{\star \star \star} P<0.001$. (d) Cultured $\gamma \delta$ TCR ${ }^{+}$IEL were stimulated on plate-bound anti-CD3. The cells were then lysed and analysed by western blotting for phosphorylation of TBK1 (S172), total TBK1 and the loading control TBP (full blots are shown in Supplementary Fig. $2 \mathrm{~d}$ ). Data are representative of four independent cultures. (e) IEL were pre-treated with $1 \mu \mathrm{M}$ of each of the following inhibitors for $1 \mathrm{~h}$ (NG-25 (TAK1 inhibitor) and MRT67307 (TBK1/IKKE inhibitor)), before stimulation on anti-CD3 for $2 \mathrm{~h}$. mRNA for IFN $\alpha$, IFN $\lambda$ and IFN $\gamma$ were measured by qRT-PCR (Uns = unstimulated). Mean and s.e.m. of four technical replicates are shown, and the data represent two independent experiments. DMSO, dimethylsulphoxide.

epithelial cells from virus. It was partially blocked by antibodies to the type I IFN receptor (IFNAR-1), or by blocking the three effectors, type I IFN, IFN $\gamma$ and TNF together (Fig. 3b,c). Thus, in the absence of any additional cell types, soluble mediators produced by activated IEL increased the antiviral resistance of IEC.

IEL activation in vivo induces a rapid antiviral response. Although the data to this point were derived by use of the MODE-K cell line, they clearly provoked the hypothesis that IEL activation induces antiviral response genes in neighbouring epithelial cells in vivo. To test this, a single low dose of anti-CD3 was administered i.p. Relative to mice receiving isotype control antibodies, antiviral genes were clearly rapidly upregulated (within $3 \mathrm{~h}$; Fig. $4 \mathrm{a}$ ), with a gradient of induction broadly correlating with IEL density along the length of the small intestine ${ }^{32}$. By fractionating total epithelium from the small intestine, the induction of Ifna, Ifnl, Ifng and Tnf could be attributable to the $\mathrm{CD} 45^{+}$fraction (mainly CD $8 \alpha^{+} \mathrm{TCR} \alpha \beta^{+}$and TCR $\gamma \delta^{+}$IEL, see Supplementary Fig. 4a), whereas the antiviral genes were upregulated in the $\mathrm{CD} 45^{-}$fraction $\left(\sim 80 \% \mathrm{EpCAM}^{+}\right.$IEC, Supplementary Fig. 4a and Fig. 4b,c). Peak induction for some genes was at $3 \mathrm{~h}$, with some mRNAs returning to baseline by $6 \mathrm{~h}$
(Supplementary Fig. 4b,c), emphasizing how rapid are the effects of activated $\mathrm{T}$ cells on epithelial cells in vivo.

At the $3 \mathrm{~h}$ time point at which gene expression was assayed, there was no major damage to the epithelial layer and no major immune cell infiltration (Supplementary Fig. 4d,e). However, because there was some villus blunting reminiscent of intestinal inflammation $^{33}$, it was appropriate to consider other possible lymphocyte sources of $\mathrm{T}$ cell activation-dependent Ifn gene expression. Thus, i.p. injection of anti-CD3 was repeated in WT mice and $3 \mathrm{~h}$ later the epithelial and lamina propria (LP) compartments separately isolated from the same guts (flow cytometry data of isolated IEL are shown in Supplementary Fig. $4 \mathrm{f}, \mathrm{g})$. qRT-PCR on the extracted layers clearly showed that IFN $\alpha$ and IFN $\lambda$ gene upregulation almost exclusively segregated with IEL, which also showed signatory high IFN $\gamma$ RNA induction (Fig. 4d). Conversely, the LP fraction displayed preferential induction of Ill7a, a known signature of LP lymphocytes, but negligible Ifna upregulation, and very weak Ifnl upregulation. Thus, there was no basis for conjecturing that intestinal $\mathrm{T}$ celldependent induction of anti-viral effectors in vivo reflected the activity of LP T cells.

Also at $3 \mathrm{~h}$ after TCR triggering in vivo, we isolated splenic $\mathrm{T}$ cells, inguinal lymph nodes (LNs) and IEL that were flow-sorted 

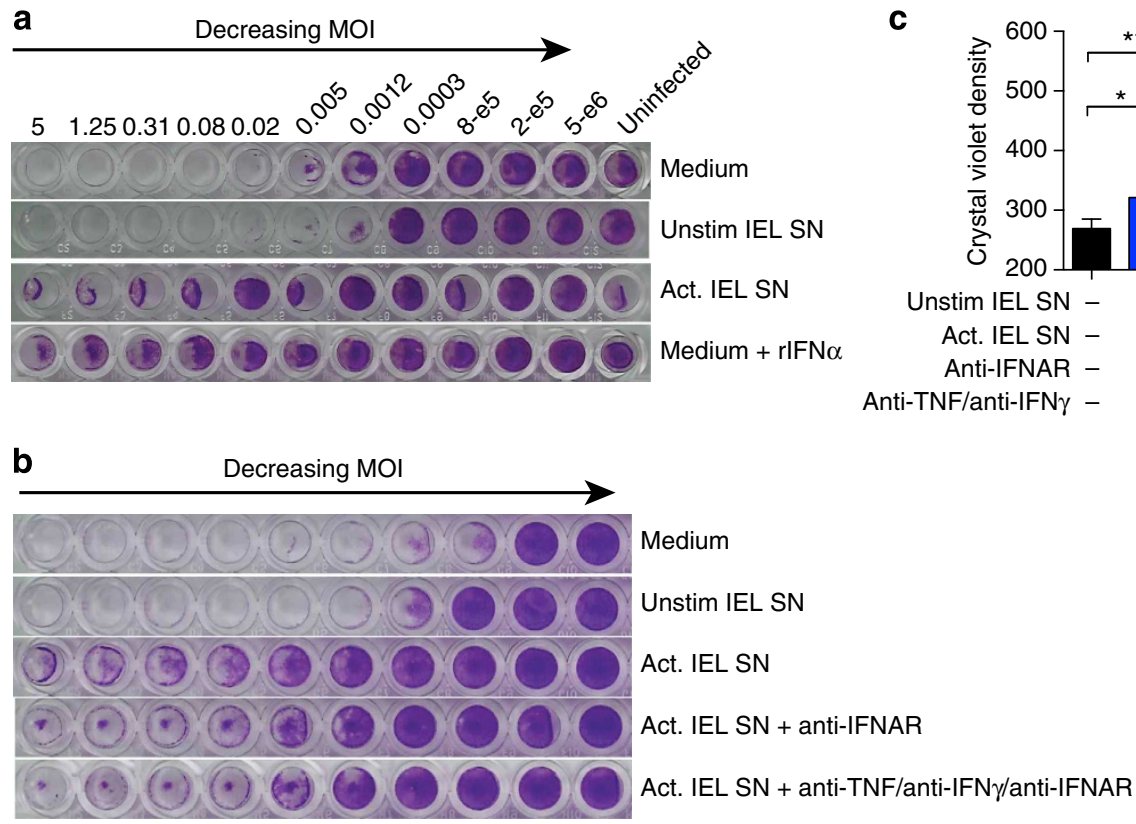

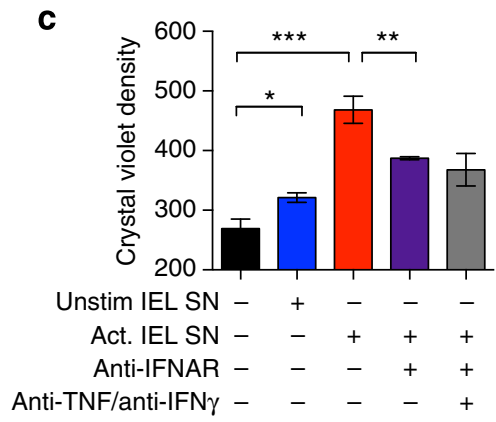

Figure 3 | IEL supernatant (SN) protects epithelial cells from virus infection in culture. (a) MODE-K cells were infected with decreasing concentrations of EMCV (encephalomyocarditis virus). Starting with an $\mathrm{MOI}$ of $5\left(3 \times 10^{5}\right.$ virus particles (leftmost)) a serial fourfold dilution was made along the row. Before infection SN of unstimulated or activated cultured IEL was added to the indicated rows. Recombinant IFN $\alpha\left(500 \mathrm{U} \mathrm{ml}^{-1}\right)$ was added as a control. (b) A similar experiment was performed as in $\mathbf{a}$, but in addition to adding IEL SN to MODE-K cells before infection, blocking antibodies against IFNAR1 and/or IFN $\gamma$ and TNF were added to IEL SN and then added to the MODE-K cells. Data are representative of three or six rows for each condition in a and $\mathbf{b}$. (c) Quantification of data in $\mathbf{b}$, significance was calculated by two-tailed unpaired $t$-test with Welch's correction, ${ }^{\star} P<0.05$, ${ }^{\star \star} P<0.01,{ }^{\star \star \star} P<0.001$.

into the main unconventional $\mathrm{T}$ cell populations $\left(\mathrm{TCR} \alpha \beta^{+}\right.$ $\mathrm{CD} 8 \alpha \alpha^{+}$IEL and TCR $\gamma \delta^{+} \mathrm{CD} 8 \alpha \alpha^{+}$IEL; Supplementary Fig. 4h). Splenic CD8 T cells and LN cells upregulated Ifna RNA to some extent, consistent with previous reports ${ }^{27}$, and Ifng mRNA very strongly, but they did not upregulate Ifnl RNA. Conversely, only purified IEL factions showed reproducible upregulation of RNAs encoding all IFN subtypes (Fig. 4e). (The relative attenuation of the type I IFN response probably reflects the fact that this is only a transiently induced gene-set relative to the time $(\sim 7 \mathrm{~h})$ required for harvesting tissue and flow cytometry-based cell sorting before RNA preparation.) Interestingly, the mild villus blunting apparent by histology (Supplementary Fig. 4d,e) has previously been associated with IFN $\alpha$ treatment of mice ${ }^{34}$, possibly reflecting anti-CD3 induced type I and type III IFN expression by IEL.

ISG upregulation in vivo depends on IFN $\alpha$ and IFN $\lambda$ receptors. To test the contribution of type I and type III IFNs to ISG upregulation in vivo, anti-CD3 was administered i.p. to mice mutant for one or both IFN receptor subtypes. The levels of induction of many ISGs were reduced in Ifnar $1^{-/}$mice, commonly to a greater degree in Ifnlr $1^{-/-}$mice, and most often to an even greater degree in Ifnar $1^{-/-}$Ifnlr $1^{-/-}$double knockout (DKO) mice (Fig. 5a). Of note, the rapid induction of Irf1, which depends primarily on IFN $\gamma$ (see Supplementary Fig. 3a), was little impaired in Ifnar $1^{-/}$Ifnlr $1^{-/}$DKO mice.

To check if antiviral protein was induced by $\mathrm{T}$ cell activation in vivo, a C57BL/6 strain was employed that harbours functional alleles of $M x 1$, which is a pseudogene in wild-type C57BL/6 mice $^{35}$. Mx1 protein rapidly accumulates in the nucleus following induction via type I or type III IFN receptors but not via IFN $\gamma \mathrm{R}^{36,37}$. Under steady-state conditions, a well-characterized antibody against Mx1 (refs 37,38) detected the specific punctate nuclear stain for Mxl protein in a very small number of LP cells (Fig. 5b and Supplementary Fig. 5a; note that the homogeneous cytoplasmic stain seen in some LP cells reflects a background signal seen also in some Mxl-deficient mice, Supplementary Fig. 5b). Conspicuously, the punctate nuclear pattern of Mx1 protein was overtly upregulated in isolated or clustered cells throughout the epithelium, consistent with an ongoing IFN response (Fig. 5b and Supplementary Fig. 5a). This activationinduced expression pattern was not seen in intestines of Ifnar $1^{-}$ ${ }^{-}$Ifnlr $1^{-/}-$DKO mice after anti-CD3 stimulation (Fig. 5b and Supplementary Fig. 5a), establishing that its TCR-driven upregulation depended on type I/type III IFN.

Pre-activation of IEL reduces susceptibility to norovirus infection. $\mathrm{MNV}$ is an enteric non-enveloped positive-sense, single-stranded RNA virus (family calicivirus) naturally prevalent among mice 39,40 . Multiple strains of this virus have been isolated that cause either acute or persistent asymptomatic infection in immunocompetent mice ${ }^{39,41}$. Mice are infected by the faecal-oral route with evidence for infection of gastrointestinal epithelial cells, macrophages and dendritic cells ${ }^{39,42}$. The capability to grow MNV in macrophage cell lines and then to infect its natural host make it an important animal model for infection by caliciviruses, including human norovirus. Furthermore, the growth of MNV is greatly inhibited by IFNs, particularly IFN $\lambda$ (ref. 43).

Therefore, to test whether prior TCR-dependent activation in the gut might increase epithelial resistance to norovirus, mice were infected orally with MNV-O7 (ref. 44) $8 \mathrm{~h}$ after preinoculation with either control or agonistic anti-CD3 antibodies i.p. After $40 \mathrm{~h}$ (a time point chosen to ensure detection of virusinfected cells), the intestines and mesenteric LNs from infected and uninfected controls were isolated, and levels of virus replication assessed by live virus titration $\left(\mathrm{TCID}_{50}\right.$ assay; Fig. $6 \mathrm{a}$ and Supplementary Fig. 6a), and by qRT-PCR for viral RNA (ORF2; Fig. 6b and Supplementary Fig. 6b), expressed in each case on a logarithmic scale. Notwithstanding some variation 
a

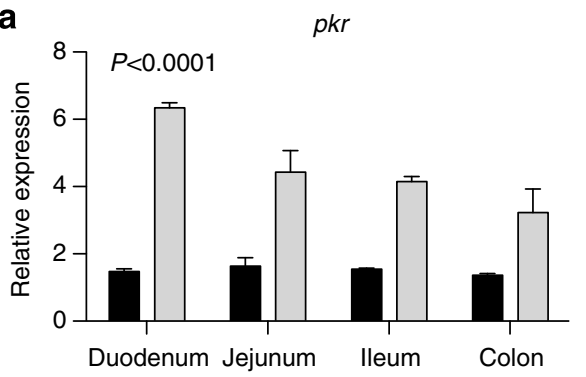

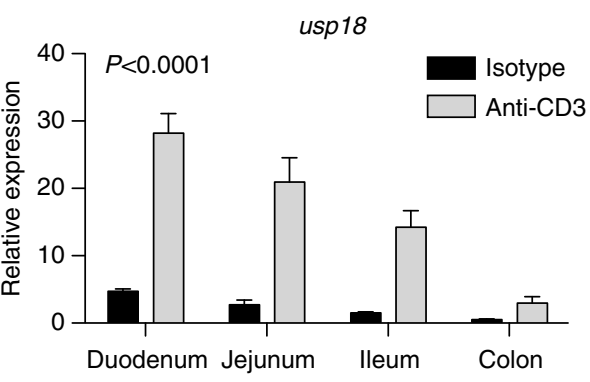
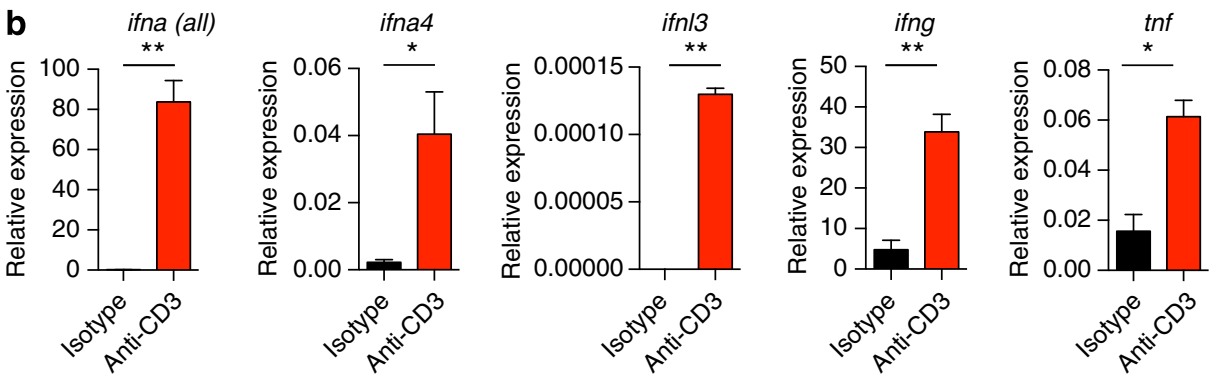

C

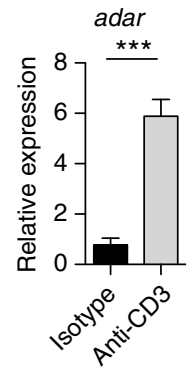

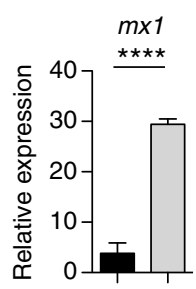

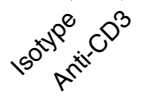

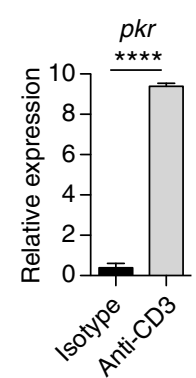

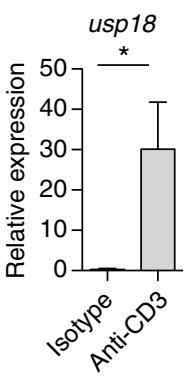

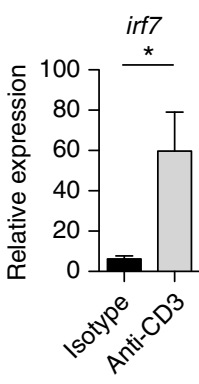

d
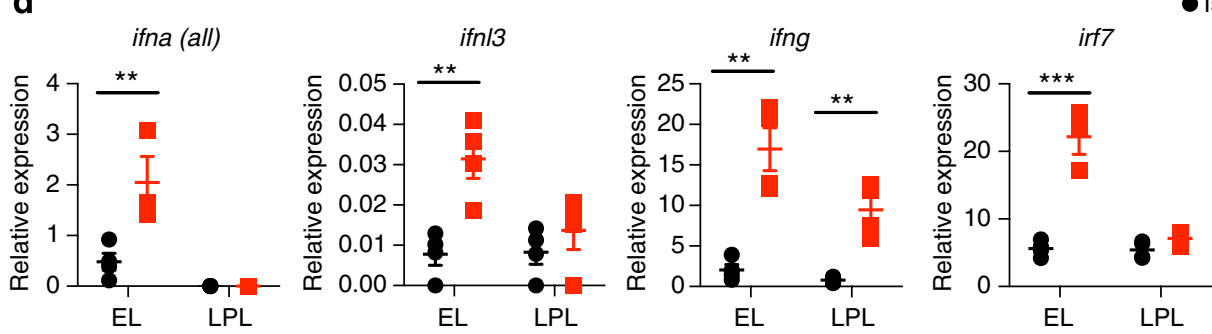

Isotype $\square$ Anti-CD3
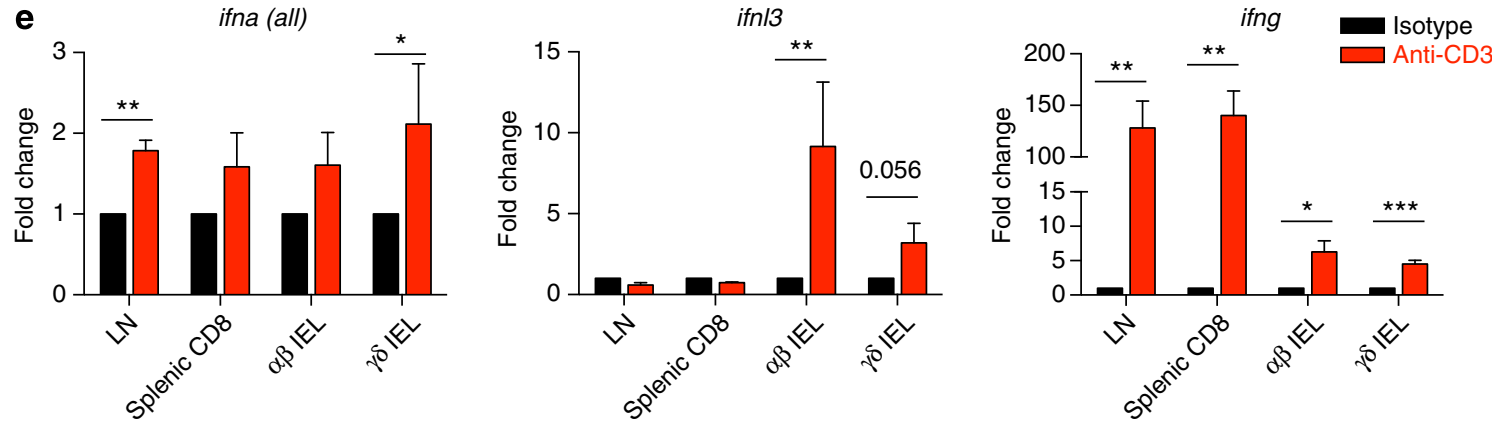

Figure 4 | Upregulation of ISGs occurs rapidly in vivo upon T cell activation in the intestine. (a) WT mice were injected i.p. with control lgG (isotype) or $50 \mu \mathrm{g}$ of anti-CD3. The intestines were harvested $3 \mathrm{~h}$ post injection, and cDNA prepared from small sections of the indicated regions: qRT-PCR was used to measure the upregulation of ISGs as before. Error bars indicate s.e.m. of three mice per condition. Shown are the $P$ values for anti-CD3 to isotype comparison, calculated by two-way analysis of variance. (b,c) The epithelial cell layer was harvested from small intestines of mice treated as in $\mathbf{a}$ and then sorted on a MACS column for CD45-positive (mainly IEL (b)) and CD45-negative (mainly intestinal epithelial cells (c)) fractions: qRT-PCR was performed as before. Expression is shown relative to TBP expression. Mean and s.e.m. of $n=3$ and the data shown are representative of four independent experiments. (d) Mice $(n=4)$ were injected i.p. with $25 \mu \mathrm{g}$ anti-CD3 antibody or isotype, and after $3 \mathrm{~h}$, the epithelial layer (EL) and LP layer (LPL) were extracted, and analysed by qRT-PCR as in b. (e) Mice were injected i.p. with $25 \mu \mathrm{g}$ anti-CD3 antibody or isotype, and after $3 \mathrm{~h}$ the inguinal lymph nodes (LNs), spleen and IEL were isolated. TCR $\gamma \delta^{+} \mathrm{CD} 8 \alpha \alpha^{+}$and TCR $\alpha \beta^{+} \mathrm{CD} 8 \alpha \alpha^{+}$IEL were flow-sorted, and analysed by qRT-PCR, alongside sorted CD $8{ }^{+}$cells from spleens and total LN cells. Normalized fold change from four experiments is shown. Statistical significance was determined by either unpaired $t$-tests $(\mathbf{b}, \mathbf{c}, \mathbf{e})$ or using the HolmSidak method (d). ${ }^{\star} P<0.05,{ }^{\star \star} P<0.01,{ }^{\star \star \star} P<0.001$. Flow cytometry of sorted cells and histology sections are in Supplementary Fig. 4. 

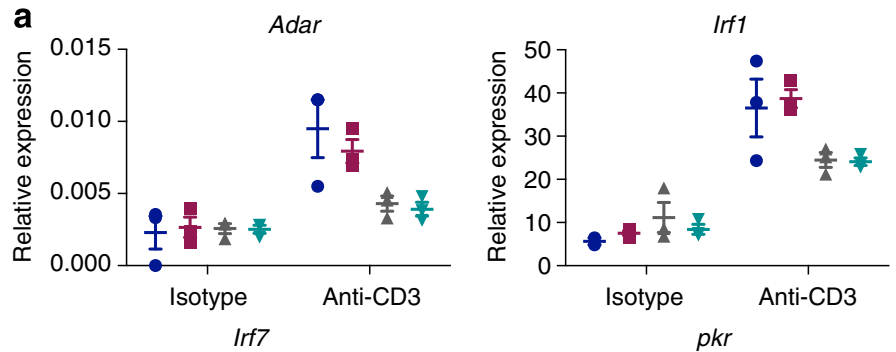

$$
\begin{aligned}
& \text { - WT } \\
& \text { IFNAR KO } \\
& \text { IFNLR KO } \\
& \text { v DKO }
\end{aligned}
$$
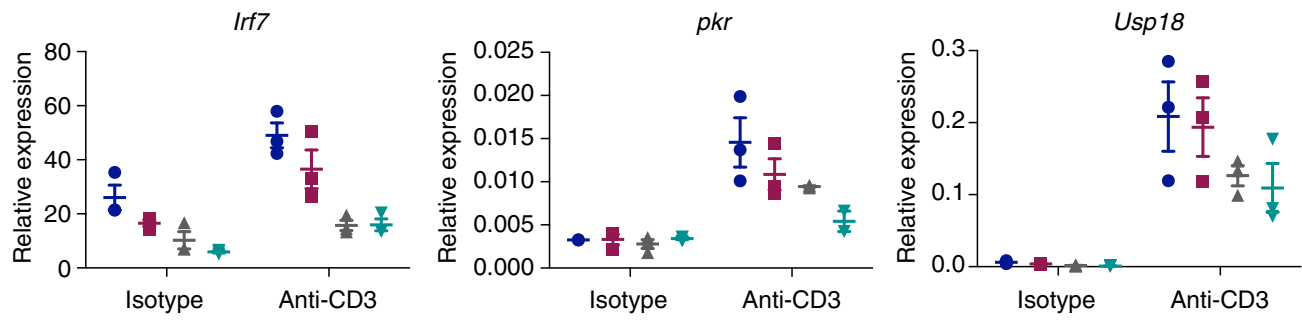

b
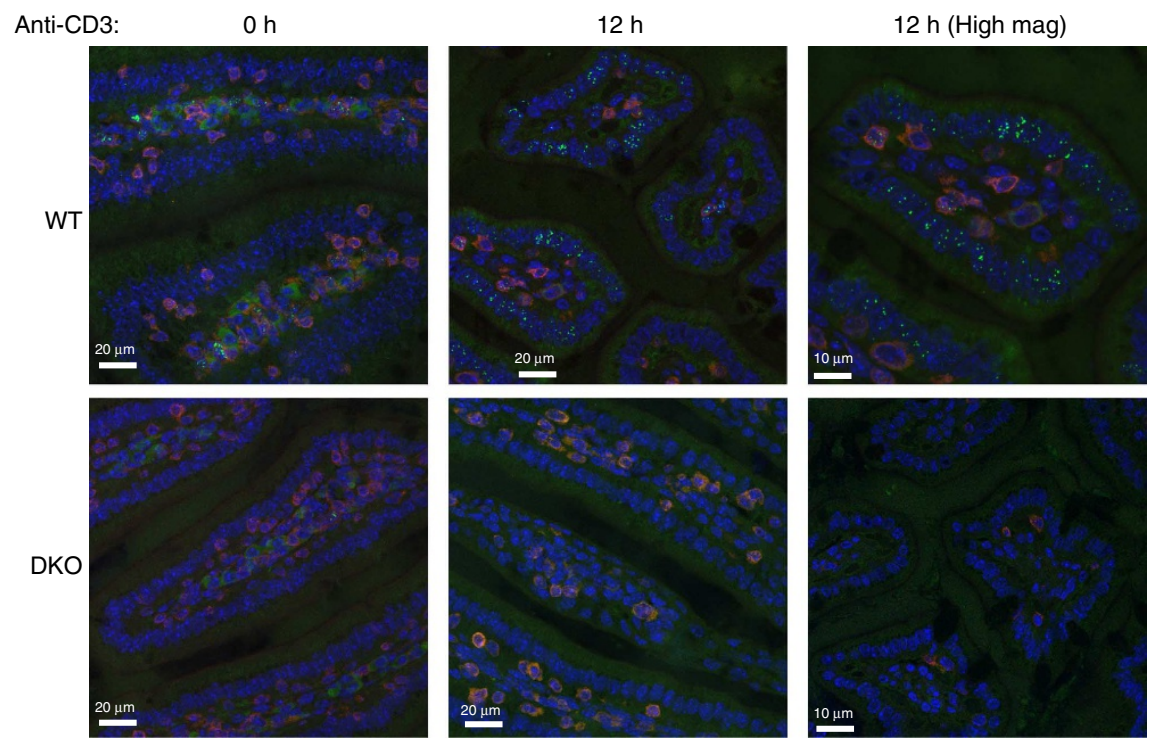

Figure 5 | Induction of ISGs depends on both type I and III IFNs in vivo. (a) B6.A2G-MxI wild type (WT), IFNAR KO, IFNLR KO and IFNAR/IFNLR DKO mice were treated with $25 \mu \mathrm{g}$ anti-CD3 or isotype control (ITC) intra-peritoneally, and intestinal tissue sections prepared after $3 \mathrm{~h}$. Induction of mRNA of the indicated ISGs was measured by qRT-PCR in wt, IFNAR KO, IFNLR KO and IFNAR/IFNLR DKO mice in small intestinal tissue, and expression relative to TBP is shown. Each data point represents an individual mouse. (b) Tissue sections from anti-CD3 i.p. injected B6.A2G-Mx1 wt and IFNAR/IFNLR DKO mice were prepared at $\mathrm{O} \mathrm{h}$ and $12 \mathrm{~h}$ after injection. Paraffin-embedded sections were stained for Mx1 protein (intra-nuclear, green), CD3 (red) and nuclei (4,6-diamidino-2-phenylindole, blue). Pictures are representative of three mice for each condition. Scale bar, $20 \mu \mathrm{m}$. Also shown are micrographs at higher magnifications (High mag) taken at $12 \mathrm{~h}$ p.i., showing the nuclear speckle-like localization of Mx1 in the wt mouse gut, but not in the IFNAR/IFNLR DKO mouse gut. See also Supplementary Fig. 5.

between groups, live virus was readily detected by $\mathrm{TCID}_{50}$ assay in cells harvested from infected mice or from infected mice pretreated with an isotype-control antibody, with consistent results obtained by qRT-PCR. However, when measured by either assay, the level of infection was reproducibly and substantively decreased in independent experiments in which mice were pre-treated with anti-CD3 (Fig. 6). Even in one case where the reduction in anti-CD3 pre-treated mice was not statistically significant (in proximal small intestine, as measured by the TCID $_{50}$ assay (Fig. 6a)), it was noteworthy that no virus could be detected in those mice (0/6), by comparison to the detection of virus in the small intestines of 5 out of 12 mice of the control groups, and that significance was reached when the same tissue was assayed by reverse transcription-PCR (Fig. 6b). Consistent results were obtained whether virus copy number was assessed relative to a control gene (Fig. 6b) or to mass of tissue (Supplementary Fig. 6b). Note too, that the results are not consistent with large amounts of virus in anti-CD3-treated mice translocating from the intestine into systemic compartments, as the viral load was also dramatically reduced (between 10 -fold and 100-fold) in the mesenteric LNs, consistent with there being a severe overall attenuation of infectious virus (Fig. 6a). Thus, TCR-dependent IEL activation in vivo functionally enhances innate resistance to norovirus.

\section{Discussion}

The very clear finding of this study is that upon activation, intestinal intraepithelial $\mathrm{T}$ cells can functionally promote innate antiviral immunity in neighbouring cells thereby contributing to timely host protection. Two questions immediately arise. The first question is the type of scenario in which IEL will be activated via the TCR. The IEL compartment is one of the largest in the body and broadly conserved across vertebrates. Data presented in this 

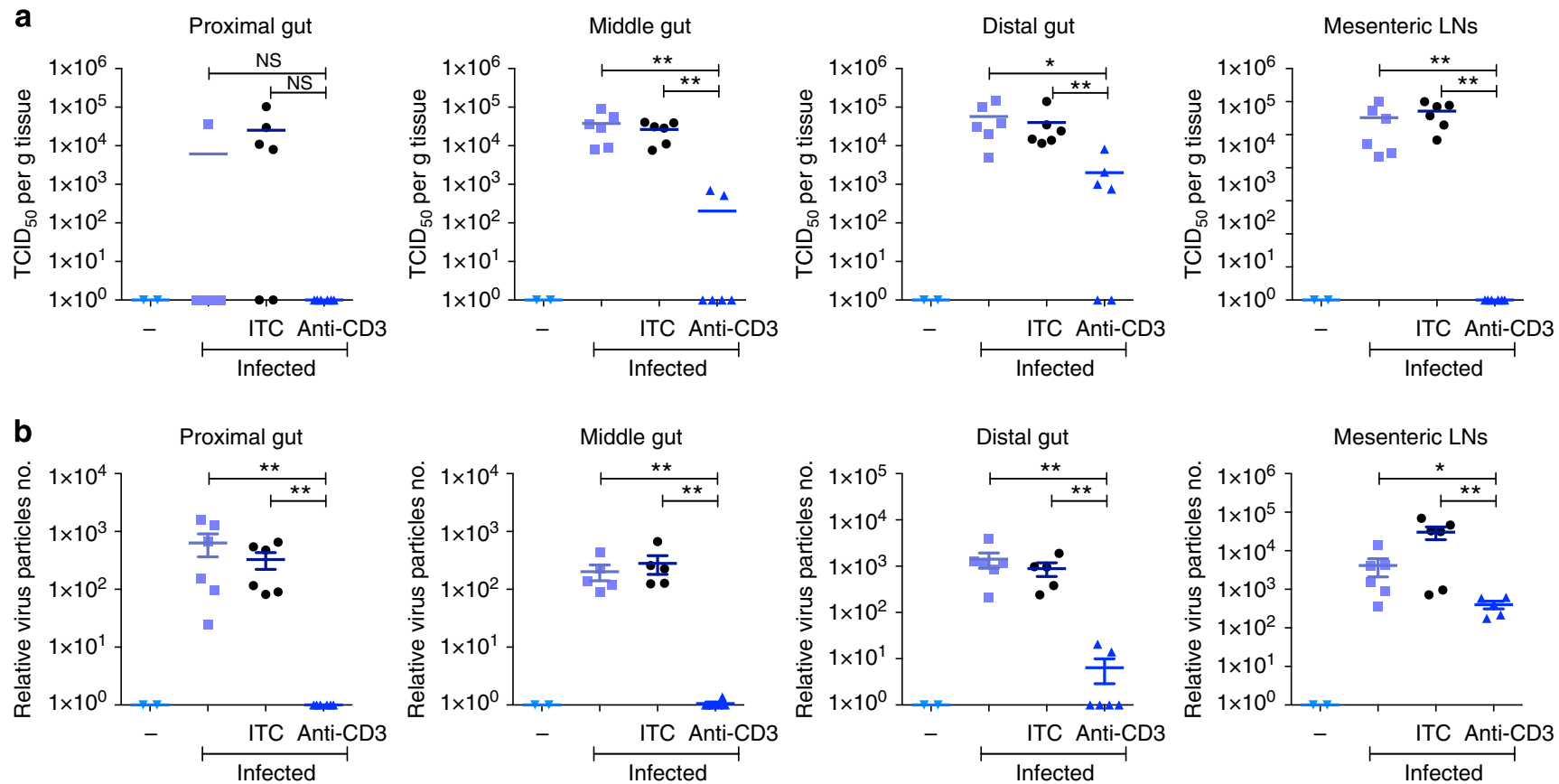

Figure 6 | Activation of IEL is protective against murine norovirus (MNV) in vivo. C57BL/6 mice were orally infected with MNV-O7, without pretreatment (no label), or $8 \mathrm{~h}$ after treating mice i.p. with anti-CD3 antibodies or the isotype control IgG (ITC). $40 \mathrm{~h}$ after infection, the organs were isolated and assayed for live virus $\left(\mathrm{TCID}_{50}\right)$ (a) or analysed by qRT-PCR for the presence of viral RNA (b). Uninfected mice were used as controls $(-)$. Virus copy numbers were estimated based on a standard curve, and then normalized for the amount of tissue section taken by normalizing to expression of a house-keeping gene (TBP) (b). Each point represents an individual animal, and statistical significance between columns was determined by two-tailed unpaired $t$-test (Kolmogorov-Smirnov method). ${ }^{\star} P<0.05,{ }^{\star \star} P<0.01$. See also Supplementary Fig. 6.

study show that multiple types of intestinal IEL can invoke antiviral effects. This is consistent with two recent studies of $\mathrm{T}_{\mathrm{RM}}$ cells, although neither study explored the functional potential of $\mathrm{T}_{\mathrm{RM}}$ cells beyond their production of conventional $\mathrm{T}$ cell mediators, particularly IFN $\gamma$ and $\mathrm{TNF}^{45,46}$. Type a IEL will likely include virus specific, memory $\mathrm{CD} 8+\mathrm{T}_{\mathrm{RM}}$ cells, deposited in the epithelium following prior infection ${ }^{47-50}$, and rapidly re-activated via the presentation of viral peptides by infected epithelial cells. Moreover, there may be biological utility to bacteria-/parasite-specific IEL activating anti-viral immunity, given recent work showing how gastrointestinal bacteria may facilitate virus infection ${ }^{51,52}$

The physiologic TCR stimuli for Type $b$ IEL have not been determined, but they are widely considered to include selfantigens that reflect cellular stress or dysregulation that is a consequence of infection. Such TCR-mediated responses can be aided by detection of 'stress-ligands' for the activating NKG2D receptor that is particularly strongly expressed by human intestinal IEL. Indeed, NKG2D is such an important component of anti-viral T- and NK cell responses that widely diverged viruses have each developed distinct immuno-evasive mechanisms ${ }^{53}$. In addition, IEL can respond to IL-15 that can be produced in high amounts by infected IEC ${ }^{54,55}$. Hence, via responses to antigen, NKG2D ligands, and 'cytokine alarmins', Type $b$ IEL may contribute to the innate phase of antiviral immunity via their sensing of the status of the tissue ${ }^{5}$. In so doing, the antiviral effects of IEL activation would complement other impacts of IEL on IEC survival, differentiation and turnover ${ }^{56,57}$ : the aggregate effect being to eradicate potentially dangerous infected epithelial cells; to promote repair of an intact epithelium; and to reduce susceptibility to further virus infection. By these several means, $\mathrm{T}$ cells can play a key role in the early phase of the response to challenge, an arena ordinarily assigned to innate myeloid cells.
The second question would ask whether activated IEL (and possibly other T cells) are over-looked, inducible sources of IFNs. Of note, the anatomical restriction of IFN $\lambda$ production to the epithelial layer of the intestine fits with the restriction of the IFN $\lambda$ receptor expression to epithelial cells and barrier surfaces. Moreover, IEL express Irf7 that encodes the major transcriptional regulator of type I and type III IFNs. IRF7 is itself a target of the type I IFN response, indicating that IEL themselves are probably responding to low levels of IFNs that they constitutively produce. Of note, a study by Ogasawara et al. of splenic $\mathrm{CD} 8^{+} \mathrm{T}$ cells also noted the cells' autocrine response to their own low levels of type I IFN $^{27}$. We have now indicated roles for the key kinases upstream of IRF7 activity, TBK1 and/or IKKe, upon TCR-triggering of IEL. Furthermore, the Ifnbl and Ifnl3 promoters also contain nuclear factor- $\kappa \mathrm{B}$-responsive elements, potentially providing an additional link of TCR triggering to the induction of IFNs ${ }^{29,58}$.

The impact of activated IEL supernatants on upregulating antiviral effectors in epithelial cells is rapid, most likely direct, and inhibited in vitro and in vivo by blocking or removing type I and type III IFN receptors. As noted previously, not all known ISGs were upregulated in epithelial cells. This may partially depend on the cohort of signal transducers and activators of transcription factors that are activated downstream of the respective IFN receptors, as has been shown for the differential response of lymphocyte subsets to IFN $\beta^{59}$. However, this study also emphasizes that the antiviral effect is promoted by a collaboration of type I and/or type III IFN with type II IFN and TNF that collectively comprise signature products of IEL. This collaboration can occur at multiple levels, involving receptor cross-talk at the level of the membrane, and further downstream, through the signalling complexes involved ${ }^{60}$.

Clearly, our work should not be taken to suggest that IEL are the exclusive source of IFNs for IEC. Rather, IEL may be important sources of IFNs in response to antigens and/or to upregulated 
NKG2D ligands, neither of which is sensed by myeloid cells. Interestingly, earlier studies showed that IEC express the type I IFN receptor apically and not basolaterally, and suggested that this would make IEC unresponsive to type I IFNs produced by other cells $^{61}$. Consistent with this, Mxl induction in IEC after rotavirus infection in vivo was more largely dependent on type III IFNs than on type I IFNs ${ }^{61}$. Nonetheless, given that IEL extend processes upwards between IEC, as do dendritic cells, it may be that apical IFNAR is specifically responsive to IFNs produced locally by IEL.

It is also the case that the impact of IFNs and the genes that they induce is not limited to antiviral functions. For example, protein kinase, dsRNA-activated (PKR), which phosphorylates the translation initiation factor eIF $2 \alpha$, modulates several stressrelated signalling pathways including autophagy by halting translation $^{62}$. Likewise, IFN-responsive transporter associated with antigen processing-1 (TAP1) is required for major histocompatibility complex-I antigen presentation in addition to its more recently discovered antiviral attributes ${ }^{26}$, and several IFN-inducible GTPases have antimicrobial activity ${ }^{63}$. Moreover, guanylate-binding protein-1 upregulation in IEC strengthens barrier integrity by reducing epithelial apoptosis 64 . Thus, IEL activation may promote such biological activities relevant to body surface integrity and epithelial turnover.

In sum, this study demonstrates an overlooked role for tissueassociated $\mathrm{T}$ cells in promoting the antiviral innate defences of the surrounding tissue. This in turn shows that a fundamental component of innate immunity can be regulated by cells classically regarded as adaptive cells, re-emphasizing caution in studies of innate immunity undertaken in scenarios of adaptive immune dysfunction, such as recombinase activating gene (RAG)-deficient mice or paediatric lymphocyte deficiencies. Finally, there is increasing public health concern about gastrointestinal virus infection in the developing and the developed worlds ${ }^{65,66}$. In considering the basis for resistance to such infections, it would seem important to consider potential contributions of $\mathrm{T}$ cells, as considered here. Indeed, T cell production of type I and III IFNs might usefully be considered in a similar clinical context to $\mathrm{T}$ cell production of cytokines such as IL-17 and IFN $\gamma$; that is to say, a potential route to immune enhancement for vaccination strategies and a target for suppression in the case of autoimmunity, inflammation or graft rejection.

\section{Methods}

Mice. Six- to twelve-week-old female C57BL/6 mice were obtained from Charles River Laboratories (Harlow). B6.A2G-Mx1 wild type mice carrying intact Mx1 alleles (WT), B6.A2G-Mx1-Ifnar1 ${ }^{-/}$mice lacking functional type I IFN receptors (IFNAR knockout (KO)), B6.A2G-Mx1-Ifnlr1 ${ }^{-/}$mice lacking functional type III IFN receptors (IFNLR KO) and B6.A2G-Mx1-Ifnar1 ${ }^{-/-}$Ifnlr1 ${ }^{-/-}$mice (DKO) lacking functional receptors for type I and III IFN were bred at the animal facility at the University of Freiburg. Animals were housed in accordance with the guidelines defined by the Federation for Laboratory Animal Science Associations (http://www.felasa.eu/recommendations) and experiments were performed in compliance with the German animal protection law (TierSchG) and the Animal (Scientific Procedures) Act UK (1986) and approved by the local animal welfare committees of the Universities of King's College London, Cambridge, Freiburg and Dundee.

Cell lines. The MODE-K small intestinal enterocyte cell line was a kind gift of D. Kaiserlain (U. Lyon, France) ${ }^{67}$. LL171 cells (L929 cells containing a stable IFN-stimulated response element-luciferase reporter plasmid (ISRE-Luc)) were a kind gift from Mireia Pelegrin (Montpellier, France).

Isolation and culture of murine small intestinal IEL. IEL were isolated from mouse small intestine as previously described ${ }^{23}$. Briefly, the small intestines were opened, freed of Peyer's patches and washed in PBS. The epithelial layer was gently scraped off using a scalpel, and incubated for 40 min in RPMI 1640 containing $10 \%$ FCS and $1 \mathrm{mM}$ dithiothreitol in a turning wheel. After centrifugation and vortexing in RPMI, the cells were passed through a nylon wool column. Isolated cells were centrifuged in a $20 \% / 40 \% / 80 \%$ Percoll density gradient at $700 \mathrm{~g}$ for $30 \mathrm{~min}$. The IEL were harvested from the 40 to $80 \%$ Percoll interface.
After isolation, IEL were stimulated on plate-bound anti-CD3 antibody $\left(1 \mu \mathrm{g} \mathrm{ml}^{-1}\right.$, $145-2 \mathrm{C} 11, \mathrm{BD}$, BioLegend) in a cocktail of cytokines (IL-2 $\left(10 \mathrm{U} \mathrm{ml}^{-1}\right), \mathrm{IL}_{-15}$ (100 $\mathrm{ng} \mathrm{ml}^{-1}$ ) (Immunotools), IL-3 (100 U ml-1), IL-4 (200 $\mathrm{U} \mathrm{ml}^{-1}$ ) (Roche)). After 2 days, cells were transferred to fresh plates and cultured with IL-2 $\left(10 \mathrm{U} \mathrm{ml}^{-1}\right)$ in RPMI 1640 Supplemented with $10 \% \mathrm{FCS}, 100 \mathrm{U} \mathrm{ml}^{-1}$ penicillin, $100 \mathrm{~g} \mathrm{ml}^{-1}$ streptomycin, $2 \mathrm{mM}$ glutamine, $1 \mathrm{mM}$ sodium pyruvate, $1 \mathrm{mM} \beta$ mercaptoethanol, 2.5 mM HEPES, and non-essential amino acids (all from Invitrogen). Cells were maintained in 96-well round-bottom plates at a concentration of 500,000 cells per $\mathrm{ml}(200 \mu \mathrm{l}$ per well $)$ at $37^{\circ} \mathrm{C}$ and $10 \% \mathrm{CO}_{2}$. Medium was replaced completely every 3-4 days.

IEL activation and blocking antibodies. For activation and experiments, IEL were seeded into 96-well round-bottom plates $(70,000-100,000$ cells per well in $200 \mu \mathrm{l})$ pre-coated with antibodies against CD3 (145-2C11, BioLegend). In blocking experiments, IEL supernatants were pre-incubated with antibodies against TNF (TN3-19), IFN $\gamma$ (R4-6A2; eBioscience), anti-IFNAR (BioLegend). Recombinant cytokines were purchased from Peprotech.

In vivo IEL activation. C57BL/6 female mice aged 8-12 weeks were intraperitoneally injected with 25 or $50 \mu \mathrm{g}$ anti-CD3 $\varepsilon$ antibody (145-2C11) or an isotype control (ITC) antibody (both BioLegend, low endotoxin, azide-free) and killed after $3 \mathrm{~h}$. The intestine was excised and flushed with PBS. Samples from different gut regions were taken for immunohistochemistry and RNA analysis. The remaining small intestine was cut longitudinally, Peyer's patches excised and cut into $1 \mathrm{~cm}$ pieces and incubated for $30 \mathrm{~min}$ in RPMI 1640 containing $10 \%$ FCS and $1 \mathrm{mM}$ dithiothreitol at room temperature in a turning wheel. Cells were spun down, resuspended in RPMI 10\% FCS and vortexed for $4 \mathrm{~min}$. The released cells were passed through a $70-\mu \mathrm{m}$ cell strainer, the remaining tissue was collected and again vortexed in RPMI 10\% FCS for 4 min. The released cells were pooled and centrifuged at $700 \times g$ for $30 \mathrm{~min}$ (no brake) in a density gradient of 80/40/20\% Percoll. Purified IEL and IEC fractions were either directly taken for flow cytometric analysis, sorting, or further purified by CD45 magnetic bead columns (Miltenyi). Purified cells were used for RNA analysis. The tissue remaining after IEL extraction was then subjected to a further extraction of the LP layer by digesting the tissue with Collagenase D $\left(500 \mu \mathrm{g} \mathrm{ml}^{-1}\right)$ and DNase $\left(50 \mu \mathrm{g} \mathrm{ml}^{-1}\right)$ for a further $1 \mathrm{~h}$ at $37^{\circ} \mathrm{C}$. The tissue was mashed through a $70-\mu \mathrm{m}$ filter, and the resulting cells also purified on a $40 \%$ Percoll layer.

Microarray analysis. MODE-K cells were seeded into six-well plates and cultured overnight. Medium was replaced with supernatant from unstimulated IEL, supernatant from anti-CD3-stimulated IEL (100\% of assay volume), or medium containing recombinant TNF and IL- $1 \alpha\left(10 \mathrm{ng} \mathrm{ml}^{-1}\right.$ and $100 \mathrm{pg} \mathrm{ml}^{-1}$, respectively). RNA was isolated using the Qiagen RNeasy extraction kit, labelled by the standard Illumina biotin labelling protocol and analysed on Illumina gene expression arrays (Mouse Ref. 8 v3) at the Bart's and the London Genome Centre. Gene expression data were analysed using Bioconductor 2.2 (http://bioconductor. org) running on R2.7.1. Normalized probe-set expression measures were calculated using $\log 2$ transformation and quantile normalization using the 'Lumi' package. To determine significant differences of expression levels between the different groups, a moderated Student's $t$-test was computed on a gene-by-gene basis using the empirical Bayes statistics in the 'Limma' package. The resultant $P$-values were adjusted for multiple testing using the false discovery rate (FDR) Benjamini and Hochberg method, where any probe sets that exhibited an adjusted $P$-value FDR $q<0.05$ were called differentially expressed. Cluster was used to draw the heatmap using average linkage clustering to cluster the genes. Differentially expressed probes were also analysed using Metacore Pathway analysis tool (Thomson Reuters) to identify enrichment of pathways and processes. The analysis employs a hypergeometric distribution to determine the most enriched gene set. Pathways or processes that showed FDR $q<0.05$ were called as enriched.

Viruses, stimuli, and cytokine induction assays. EMCV strain pEC9 was a gift from Dr Ian Kerr. MODE-K cells were plated at 30,000 cells per well in 96-well flatbottom plates. The cells were infected with decreasing concentrations of EMCV starting with an MOI of $100\left(3 \times 10^{5}\right.$ virus particles (leftmost) $)$ then a serial fourfold dilution was made along the row. One column of cells was left uninfected to control for cell proliferation and viability. Where indicated, the cells were pretreated overnight with 1:1 diluted IEL supernatant, with/without blocking antibodies. Four rows were prepared for each treatment. Twenty-four hours post infection, cells remaining in the well were fixed and stained with crystal violet. A clear well indicates cell death by virus infection. To quantify the crystal violet data, the 8-bit images of 96-well plates were analysed by measuring mean density with background density subtracted in each well. For stimulation and cytokine induction assays, MODE-K cells were seeded in 48 -well plates at $4 \times 10^{5}$ cells per ml and treated with IEL supernatant or recombinant cytokines for $6 \mathrm{~h}$ unless otherwise indicated.

IFN $\alpha$ detection. IFN $\alpha$ was measured by sandwich ELISA as described previously ${ }^{68}$. Total IFN $\alpha / \beta$ were measured by titration on LL171 (ISRE-Luciferase 
containing) cells and compared with recombinant human IFN-A/D used as a cytokine standard.

Quantitative real-time reverse transcription-PCR. Samples were stored in RNAlater (Ambion) or directly frozen in RLT buffer, RNA was isolated with a Qiagen RNeasy kit, transcribed into cDNA and analysed in comparison to TATA box binding protein (TBP) on a ViiA7 Real-time PCR machine (Applied Biosystems). All primer sequences are provided in Supplementary Table 1.

Immunohistochemistry. Gut tissue was fixed overnight in $10 \%$ neutral-buffered formalin, paraffin embedded and sectioned at $4-\mu \mathrm{m}$ thickness for staining with mouse anti-Mx1 (clone M143) ${ }^{38}$ or anti-CD3 $\varepsilon$ (rabbit polyclonal, Dako). Secondary antibodies used were AlexaFluor 488- and 647-labelled antibodies from Molecular Probes (Invitrogen). Sections were mounted in Vectashield containing 4,6-diamidino-2-phenylindole to stain nuclei.

Imaging. Images were acquired at room temperature on a Zeiss-LSM710 confocal microscope with a Plan-Apochromat $\times 40 / 1.3$ Oil/DIC objective and Zen image acquisition software or on a Leica SP5 laser-scanning confocal microscope equipped with a $\times 40 / 1.4$ numerical aperture PL APO oil objective. All images were acquired as z-stacks of $10 \mu \mathrm{m}$ thickness and maximum projections presented using the Leica application suite software. Images were exported and processed using Volocity software (Improvision) or ImageJ.

In vivo virus infection. The $\mathrm{MNV}$ strain $\mathrm{O} 7$ ( $\mathrm{MNV}-\mathrm{O} 7)$ was isolated from the faeces of a STAT1 $1^{-/-}$mouse, grown in BV2 cells ${ }^{69}$ and used at passage 3 . The strain establishes a persistent, and usually non-pathogenic, infection in immunocompetent mice ${ }^{44}$. Six- to eight-week-old female C57BL/6 mice were injected i.p. with either $25 \mu \mathrm{g}$ anti-CD3 $\varepsilon$ antibody (145-2C11) or isotype control antibody or were left untreated. After $8 \mathrm{~h}$, mice were then infected with $5 \times 10^{6}$ $\mathrm{TCID}_{50} \mathrm{MNV}-\mathrm{O} 7$ by oral gavage and killed at $40 \mathrm{~h}$ post-infection. Tissues were removed immediately and the intestine flushed through with PBS before sectioning. Sections were preserved in RNAlater for qRT-PCR or were frozen at $-80^{\circ} \mathrm{C}$ for assays to titre live virus. Sections were weighed, homogenized in PBS, freeze-thawed, supernatant clarified and the resulting supernatant used in limiting dilution infection assays. Live virus titre was calculated by the Reed-Muench $\operatorname{method}^{70}$

Statistics. Statistical analyses were performed using Prism 6.0 (GraphPad), and the tests used are indicated in the figure legends. Differences were considered significant when $P<0.05$.

\section{References}

1. Hayday, A., Theodoridis, E., Ramsburg, E. \& Shires, J. Intraepithelial lymphocytes: exploring the Third Way in immunology. Nat. Immunol. 2, 997-1003 (2001).

2. Gebhardt, T., Mueller, S. N., Heath, W. R. \& Carbone, F. R. Peripheral tissue surveillance and residency by memory $\mathrm{T}$ cells. Trends Immunol. 34, 27-32 (2013).

3. Hayday, A. \& Gibbons, D. Brokering the peace: the origin of intestinal T cells. Mucosal Immunol. 1, 172-174 (2008)

4. Cheroutre, H., Lambolez, F. \& Mucida, D. The light and dark sides of intestinal intraepithelial lymphocytes. Nat. Rev. Immunol. 11, 445-456 (2011).

5. Hayday, A. C. $\gamma \delta$ T cells and the lymphoid stress-surveillance response. Immunity 31, 184-196 (2009).

6. Shires, J., Theodoridis, E. \& Hayday, A. C. Biological insights into TCR $\gamma \delta+$ and TCR $\alpha \beta+$ intraepithelial lymphocytes provided by serial analysis of gene expression (SAGE). Immunity 15, 419-434 (2001).

7. Chen, Y., Chou, K., Fuchs, E., Havran, W. L. \& Boismenu, R. Protection of the intestinal mucosa by intraepithelial $\gamma \delta$ T cells. Proc. Natl Acad. Sci. USA 99, 14338-14343 (2002)

8. Fahrer, A. M. et al. Attributes of $\gamma \delta$ intraepithelial lymphocytes as suggested by their transcriptional profile. Proc. Natl Acad. Sci. USA 98, 10261-10266 (2001)

9. Ivanov, I. I. et al. Induction of intestinal Th17 cells by segmented filamentous bacteria. Cell 139, 485-498 (2009).

10. Gaboriau-Routhiau, V. et al. The key role of segmented filamentous bacteria in the coordinated maturation of gut helper $\mathrm{T}$ cell responses. Immunity 31, 677-689 (2009)

11. Round, J. L. \& Mazmanian, S. K. The gut microbiota shapes intestinal immune responses during health and disease. Nat. Rev. Immunol. 9, 313-323 (2009).

12. Ismail, A. S. et al. $\gamma \delta$ intraepithelial lymphocytes are essential mediators of host-microbial homeostasis at the intestinal mucosal surface. Proc. Natl Acad. Sci. USA 108, 8743-8748 (2011)
13. Roberts, S. J. et al. T-cell $\alpha \beta^{+}$and $\gamma \delta^{+}$deficient mice display abnormal but distinct phenotypes toward a natural, widespread infection of the intestinal epithelium. Proc. Natl Acad. Sci. USA 93, 11774-11779 (1996).

14. Smith, A. L. \& Hayday, A. C. An $\alpha \beta$ T-cell-independent immunoprotective response towards gut coccidia is supported by $\gamma \delta$ cells. Immunology 101, 325-332 (2000)

15. Ramsburg, E., Tigelaar, R., Craft, J. \& Hayday, A. Age-dependent requirement for $\gamma \delta \mathrm{T}$ cells in the primary but not secondary protective immune response against an intestinal parasite. J. Exp. Med. 198, 1403-1414 (2003).

16. Adkins, B., Leclerc, C. \& Marshall-Clarke, S. Neonatal adaptive immunity comes of age. Nat. Rev. Immunol. 4, 553-564 (2004)

17. Kuo, S., Guindy, El, A., Panwala, C. M., Hagan, P. M. \& Camerini, V. Differential appearance of $\mathrm{T}$ cell subsets in the large and small intestine of neonatal mice. Pediatr. Res. 49, 543-551 (2001).

18. Williams, A. M. et al. Effects of microflora on the neonatal development of gut mucosal T cells and myeloid cells in the mouse. Immunology 119, 470-478 (2006).

19. Sydora, B. C., Jamieson, B. D., Ahmed, R. \& Kronenberg, M. Intestinal intraepithelial lymphocytes respond to systemic lymphocytic choriomeningitis virus infection. Cell Immunol. 167, 161-169 (1996).

20. London, S. D., Cebra, J. J. \& Rubin, D. H. Intraepithelial lymphocytes contain virus-specific, MHC-restricted cytotoxic cell precursors after gut mucosal immunization with reovirus serotype 1/Lang. Reg. Immunol. 2, 98-102 (1989).

21. Dharakul, T., Rott, L. \& Greenberg, H. B. Recovery from chronic rotavirus infection in mice with severe combined immunodeficiency: virus clearance mediated by adoptive transfer of immune $\mathrm{CD} 8{ }^{+} \mathrm{T}$ lymphocytes. J. Virol. 64, 4375-4382 (1990).

22. Müller, S., Bühler-Jungo, M. \& Mueller, C. Intestinal intraepithelial lymphocytes exert potent protective cytotoxic activity during an acute virus infection. J. Immunol. 164, 1986-1994 (2000).

23. Bas, A. et al. Butyrophilin-like 1 encodes an enterocyte protein that selectively regulates functional interactions with T lymphocytes. Proc. Natl Acad. Sci. USA 108, 4376-4381 (2011).

24. Der, S. D., Zhou, A., Williams, B. R. G. \& Silverman, R. H. Identification of genes differentially regulated by interferon $\alpha, \beta$, or $\gamma$ using oligonucleotide arrays. Proc. Natl. Acad. Sci. USA 95, 15623-15628 (1998).

25. Zhou, Z. et al. Type III interferon (IFN) induces a type I IFN-like response in a restricted subset of cells through signaling pathways involving both the Jak-STAT pathway and the mitogen-activated protein kinases. J. Virol. 81, 7749-7758 (2007).

26. Liu, S.-Y., Sanchez, D. J., Aliyari, R., Lu, S. \& Cheng, G. Systematic identification of type I and type II interferon-induced antiviral factors. Proc. Natl Acad. Sci. USA 109, 4239-4244 (2012).

27. Ogasawara, K. et al. Requirement of the IFN- $\alpha / \beta$-induced CXCR3 chemokine signalling for $\mathrm{CD}^{+}{ }^{+} \mathrm{T}$ cell activation. Genes Cells 7, 309-320 (2002).

28. Honda, K. et al. IRF-7 is the master regulator of type-I interferon-dependent immune responses. Nature 434, 772-777 (2005).

29. Osterlund, P. I., Pietilä, T. E., Veckman, V., Kotenko, S. V. \& Julkunen, I. IFN regulatory factor family members differentially regulate the expression of type III IFN (IFN- $\lambda$ ) genes. J. Immunol. 179, 3434-3442 (2007).

30. Levy, D. E., Marié, I. J. \& Durbin, J. E. Induction and function of type I and III interferon in response to viral infection. Curr. Opin. Virol. 1, 476-486 (2011).

31. Clark, K. et al. Novel cross-talk within the IKK family controls innate immunity. Biochem. J. 434, 93-104 (2011).

32. Tamura, A. et al. Distribution of two types of lymphocytes (intraepithelial and lamina-propria-associated) in the murine small intestine. Cell Tissue Res. 313, 47-53 (2003)

33. Radojevic, N. et al. Characterization of enteric functional changes evoked by in vivo anti-CD3 T cell activation. Am. J. Physiol. 276, R715-R723 (1999).

34. Garside, P., Felstein, M. V., Green, E. A. \& Mowat, A. M. The role of interferon $\alpha / \beta$ in the induction of intestinal pathology in mice. Immunology 74, 279-283 (1991).

35. Koerner, I., Kochs, G., Kalinke, U., Weiss, S. \& Staeheli, P. Protective role of beta interferon in host defense against influenza A virus. J. Virol. 81, 2025-2030 (2007).

36. Sommereyns, C., Paul, S., Staeheli, P. \& Michiels, T. IFN-Lambda (IFN- $\lambda$ ) is expressed in a tissue-dependent fashion and primarily acts on epithelial cells in vivo. PLoS Pathog. 4, e1000017 (2008)

37. Holzinger, D. et al. Induction of MxA gene expression by influenza A virus requires type I or type III interferon signaling. J. Virol. 81, 7776-7785 (2007).

38. Flohr, F., Schneider-Schaulies, S., Haller, O. \& Kochs, G. The central interactive region of human MxA GTPase is involved in GTPase activation and interaction with viral target structures. FEBS Lett. 463, 24-28 (1999).

39. Karst, S. M., Wobus, C. E., Lay, M., Davidson, J. \& Virgin, H. W. STAT1dependent innate immunity to a Norwalk-like virus. Science 299, 1575-1578 (2003). 
40. Wobus, C. E., Thackray, L. B. \& Virgin, H. W. Murine norovirus: a model system to study norovirus biology and pathogenesis. J. Virol. 80, 5104-5112 (2006).

41. Hsu, C. C., Riley, L. K., Wills, H. M. \& Livingston, R. S. Persistent infection with and serologic cross-reactivity of three novel murine noroviruses. Comp. Med 56, 247-251 (2006).

42. Wobus, C. E. et al. Replication of Norovirus in cell culture reveals a tropism for dendritic cells and macrophages. PLoS Biol. 2, e432 (2004).

43. Nice, T. J. et al. Interferon- $\lambda$ cures persistent murine norovirus infection in the absence of adaptive immunity. Science 347, 269-273 (2015).

44. Shortland, A. et al. Pathology caused by persistent murine norovirus infection. J. Gen. Virol. 95, 413-422 (2014).

45. Ariotti, S. et al. T cell memory. Skin-resident memory CD8 + T cells trigger a state of tissue-wide pathogen alert. Science 346, 101-105 (2014).

46. Schenkel, J. M. et al. T cell memory. Resident memory CD8 T cells trigger protective innate and adaptive immune responses. Science 346, 98-101 (2014).

47. Gebhardt, T. et al. Memory T cells in nonlymphoid tissue that provide enhanced local immunity during infection with herpes simplex virus. Nat. Immunol. 10, 524-530 (2009).

48. Schenkel, J. M., Fraser, K. A., Vezys, V. \& Masopust, D. Sensing and alarm function of resident memory CD8 + T cells. Nat. Immunol. 14, 509-513 (2013).

49. Cauley, L. S. \& LeFrancois, L. Guarding the perimeter: protection of the mucosa by tissue-resident memory T cells. Mucosal Immunol. 6, 14-23 (2012).

50. Ariotti, S. et al. Tissue-resident memory CD8 ${ }^{+} \mathrm{T}$ cells continuously patrol skin epithelia to quickly recognize local antigen. Proc. Natl Acad. Sci. USA 109, 19739-19744 (2012).

51. Kuss, S. K. et al. Intestinal microbiota promote enteric virus replication and systemic pathogenesis. Science 334, 249-252 (2011).

52. Kane, M. et al. Successful transmission of a retrovirus depends on the commensal microbiota. Science 334, 245-249 (2011).

53. Eagle, R. A. \& Trowsdale, J. Promiscuity and the single receptor: NKG2D. Nat. Rev. Immunol. 7, 737-744 (2007).

54. Hirose, K. et al. Interleukin-15 may be responsible for early activation of intestinal intraepithelial lymphocytes after oral infection with Listeria monocytogenes in rats. Infect. Immun. 66, 5677-5683 (1998).

55. Okazawa, A. et al. Human intestinal epithelial cell-derived interleukin (IL)-18, along with IL-2, IL-7 and IL-15, is a potent synergistic factor for the proliferation of intraepithelial lymphocytes. Clin. Exp. Immunol. 136, 269-276 (2004).

56. Saurer, L. et al. Virus-induced activation of self-specific TCR $\alpha \beta \operatorname{CD} 8 \alpha \alpha$ intraepithelial lymphocytes does not abolish their self-tolerance in the intestine. J. Immunol. 172, 4176-4183 (2004).

57. Komano, H. et al. Homeostatic regulation of intestinal epithelia by intraepithelial $\gamma \delta$ T cells. Proc. Natl Acad. Sci. USA 92, 6147-6151 (1995).

58. Onoguchi, K. et al. Viral infections activate types I and III interferon genes through a common mechanism. J. Biol. Chem. 282, 7576-7581 (2007).

59. van Boxel-Dezaire, A. H. H. et al. Major differences in the responses of primary human leukocyte subsets to IFN- $\beta$. J. Immunol. 185, 5888-5899 (2010).

60. Taniguchi, T. \& Takaoka, A. A weak signal for strong responses: interferon- $\alpha / \beta$ revisited. Nat. Rev. Mol. Cell. Biol. 2, 378 (2001).

61. Pott, J. et al. IFN- $\lambda$ determines the intestinal epithelial antiviral host defense. Proc. Natl Acad. Sci. USA 108, 7944-7949 (2011).

62. Hotamisligil, G. S. Endoplasmic reticulum stress and the inflammatory basis of metabolic disease. Cell 140, 900-917 (2010).

63. MacMicking, J. D. IFN-inducible GTPases and immunity to intracellular pathogens. Trends Immunol. 25, 601-609 (2004).

64. Schnoor, M., Betanzos, A., Weber, D. A. \& Parkos, C. A. Guanylate-binding protein-1 is expressed at tight junctions of intestinal epithelial cells in response to interferon-gamma and regulates barrier function through effects on apoptosis. Mucosal Immunol. 2, 33-42 (2009).

65. Lopman, B. et al. Increase in viral gastroenteritis outbreaks in Europe and epidemic spread of new norovirus variant. Lancet 363, 682-688 (2004).

66. Monroe, S. S. Control and prevention of viral gastroenteritis. Emerging Infect. Dis 17, 1347-1348 (2011).

67. Vidal, K., Grosjean, I., Revillard, J. P., Gespach, C. \& Kaiserlian, D. Immortalization of mouse intestinal epithelial cells by the SV40-large T gene. Phenotypic and immune characterization of the MODE-K cell line. J. Immunol. Methods 166, 63-73 (1993).

68. Asselin-Paturel, C. et al. Mouse type I IFN-producing cells are immature APCs with plasmacytoid morphology. Nat. Immunol. 2, 1144-1150 (2001).

69. Blasi, E., Barluzzi, R., Bocchini, V., Mazzolla, R. \& Bistoni, F. Immortalization of murine microglial cells by a v-raf/v-myc carrying retrovirus. $J$. Neuroimmunol. 27, 229-237 (1990).

70. Reed, L. J. \& Muench, H. A simple and reliable method of estimating fifty per cent end points. Am. J. Hyg. 27, 493-497 (1938).

\section{Acknowledgements}

Support was provided by the Wellcome Trust (A.C.H., J.L.H., G.R) and Cancer Research UK (A.C.H.), Department of Health via the National Institute for Health Research (NIHR) comprehensive Biomedical Research Centre award to Guy's \& St Thomas' NHS Foundation Trust (L.A.-D.; A.C.H.); Marie Curie and EMBO fellowships (M.S.). We thank Professor D. Cantrell for generous support of M.S.; Dr D. Kaiserlien (Lyon) for the gift of MODE-K cells; Dr B. Spencer-Dene for histological stainings; Dr P. East for contributing to microarray data analysis, and our many colleagues for useful discussions and criticisms, particularly Dr V. Hornung. We acknowledge the staffs of the flow cytometry and animal care facilities of the Francis Crick Institute, Lincoln's Inn Fields Laboratories, London, UK, King's College London, and the Universities of Freiburg, Cambridge, and Dundee.

\section{Author contributions}

M.S., L.A.-D., J.C., T.M. and D.G. designed and undertook experiments and analysed data; P.C. analysed microarray data; G.R. conducted experiments and analysed data; C.R.eS., P.S., B.A.B. and J.L.H. contributed ideas and key reagents and helped design and interpret experiments; M.S. and A.C.H. designed the study and individual experiments, analysed the data and wrote the manuscript.

\section{Additional information}

Accession codes. The microarray data have been deposited in the NCBI Gene Expression Omnibus (GEO) database with accession code GSE63364.

Supplementary Information accompanies this paper at http://www.nature.com/ naturecommunications

Competing financial interests: The authors declare no competing financial interests.

Reprints and permission information is available online at http://npg.nature.com/ reprintsandpermissions/

How to cite this article: Swamy, M. et al. Intestinal intraepithelial lymphocyte activation promotes innate antiviral resistance. Nat. Commun. 6:7090 doi: 10.1038/ncomms8090 (2015).

This work is licensed under a Creative Commons Attribution 4.0 International License. The images or other third party material in this article are included in the article's Creative Commons license, unless indicated otherwise in the credit line; if the material is not included under the Creative Commons license, users will need to obtain permission from the license holder to reproduce the material. To view a copy of this license, visit http://creativecommons.org/licenses/by/4.0/ 